\title{
Workshop report: Introducing pay-for-performance (P4P) approach and increase utilization of maternal, newborn, and child health services in Bangladesh
}

Md. Noorunnabi Talukder

Population Council

Ubaidur Rob

Population Council

Ismat Ara Hena

Population Council

Farhana Akter

Population Council

Mohammad Ataur Rahman

Population Council

Follow this and additional works at: https://knowledgecommons.popcouncil.org/departments_sbsr-rh fra next page for additional authors

Part of the Demography, Population, and Ecology Commons, Family, Life Course, and Society Commons, Gender and Sexuality Commons, International Public Health Commons, Maternal and Child Health Commons, Medicine and Health Commons, and the Women's Health Commons How does access to this work benefit you? Let us know!

\section{Recommended Citation}

Talukder, Md. Noorunnabi, Ubaidur Rob, Ismat Ara Hena, Farhana Akter, Mohammad Ataur Rahman, and Md. Julkarnayeen. 2010. "Workshop report: Introducing pay-for-performance (P4P) approach and increase utilization of maternal, newborn, and child health services in Bangladesh." Dhaka: Population Council. 


\section{Authors}

Md. Noorunnabi Talukder, Ubaidur Rob, Ismat Ara Hena, Farhana Akter, Mohammad Ataur Rahman, and Md. Julkarnayeen 


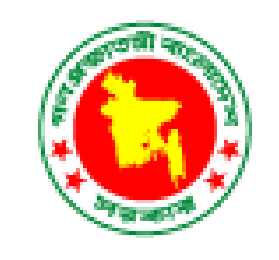

\section{Workshop Report}

Introducing Pay-for-Performance (P4P) Approach and Increase Utilization of Maternal, Newborn and

Child Health Services in Bangladesh

\section{Population Council, Bangladesh}

August 2010 


\title{
Workshop Report
}

Introducing Pay-for-Performance (P4P) Approach and Subsidized Coupons to Increase Utilization of Maternal, Newborn and

Child Health Services in Bangladesh

\author{
Md. Noorunnabi Talukder \\ Ubaidur Rob \\ Laila Rahman \\ Ismat Ara Hena \\ Farhana Akter \\ Mohammad Ataur Rahman \\ Md. Julkarnayeen
}

Population Council, Bangladesh

August 2010

This publication is made possible through the financial support of UNICEF/Bangladesh. The opinions expressed herein are those of the authors and do not reflect the views of the Population Council and UNICEF/Bangladesh. 
Suggested citation:

Population Council. 2010. "Workshop Report: Introducing pay-for-performance (P4P) approach and increase utilization of maternal, newborn and child bealth services in Bangladesh." Dhaka, Bangladesh: Population Council. 


\section{Acknowledgements}

Population Council expresses sincere gratitude to UNICEF for their interest and financial contribution towards carrying out policy workshops on Pay-for-Performance (P4P) approach.

Population Council is grateful to Professor Khandoker Md. Shefayet Ullah, Additional Director General, Directorate General of Health Services (DGHS), Ministry of Health and Family Welfare (MOHFW), who inaugurated the national workshop as the Chief Guest. We are indebted to Dr. A.B.M. Jahangir Alam, Director, Primary Health Care and Line Director, Essential Services Delivery, DGHS for chairing the national workshop and delivering a thoughtful speech. We would like to extend our heartfelt thanks to Dr. Md. Anwar Hossain Munshi, Joint Chief (Joint Secretary) Health Economics Unit, MOHFW and Dr. Jafar Ahmad Hakim, Director, Maternal and Child Health Services and Line Director, Maternal ChildReproductive Health Services, Directorate General of Family Planning for their presence and contribution as Special Guest at the national workshop. The Council also expresses sincere thanks to Dr. Kazi Md. Habibur Rahman, Program Manager, Reproductive Health, DGHS, Dr. Sushil Ranjan Howlader, Professor, Institute of Health Economics, University of Dhaka and Dr. S.A.J.M. Musa, Assistant Director, Coordination, DGHS for moderating group sessions.

Similarly, policymakers, program managers and service providers provided support and cooperation in organizing workshops at the district level. We are grateful to Dr. A.B.M. Jahangir Alam who attended as the Chief Guest and Dr. Kazi Md. Habibur Rahman who was present as Special Guest in three district workshops. We express our sincere gratitude to Dr. Jafar Ahmad Hakim who was present as Special Guest in two district workshops. We sincerely thank Dr. Md. Abdul Hakim, Civil Surgeon, Jamalpur, Dr. Md. Rafiqul Islam, Civil Surgeon, Gaibandha, Dr. Md. Abdur Rashid Akanda, Civil Surgeon, Nilphamari and Dr. Md Golam Mostafa, Civil Surgeon, Kurigram who chaired the district level workshops. Thanks are also due to Dr. Nargis Begum, Deputy Director-Family Planning, Jamlapur, Dr. Md. Ehsanul Haque, Assistant Director-Clinical Contraception, Nilphamari and Dr. Ferdous Hossain Manju, Deputy DirectorFamily Planning, Gaibandha, and Dr. Md. Shamsuddoha, Deputy Director-Family Planning, Kurigram for their welcome speeches at respective district workshops.

We sincerely thank Dr. Kazi Md. Habibur Rahman, Program Manager, RH, DGHS, Dr. Azizul Alim, Deputy Program Manager, Reproductive Health, DGHS, Dr. Akhter Jahan, Deputy Program Manager, Maternal and Neonatal Health, DGHS, Dr. Iqbal Ahmed, Deputy Program Manager, DGHS, Dr. Md. Omar Ali Sarkar, Deputy Program Manager, DGHS, Dr. Nazrul Islam, Former Deputy Program Manager, Emergency Obstetric Care and Demand-Side Financing, DGHS, and Dr. Md. Khairul Hasan, Health Officer, Maternal Health, UNICEF who moderated group discussions at district workshops.

The Council expresses sincere gratitude to Dr. A.B.M. Jahangir Alam, Dr. Kazi Md. Habibur Rahman and Dr. Azizul Alim for their guidance and all-out cooperation.

We are grateful to Dr. Lubana Ahmed of UNICEF and the project manager of the P4P project for her technical assistance and useful inputs to the keynote paper. We sincerely thank Dr. Monira Parveen and Dr. Riad Mahmud of UNICEF for their insights and cooperation; and Dr. Riad Mahmud for presenting keynote paper in district workshops. The contribution of the regional and district-level staff of UNICEF, BRAC and CARE in organizing workshops is acknowledged with high appreciation.

We are thankful to all the participants who attended and contributed to the workshops. Special heartfelt thanks are due to Population Council staff members for their sincere efforts in organizing the workshops. 


\section{Abbreviations}

$\begin{array}{ll}\text { AFWO } & \text { Assistant Family Welfare Officer } \\ \text { AMTSL } & \text { Active Management of Third Stage Labor } \\ \text { AUFPO } & \text { Assistant Upazila Family Planning Officer } \\ \text { BMA } & \text { Bangladesh Medical Association } \\ \text { BEmOC } & \text { Basic Emergency Obstetric Care } \\ \text { CEmOC } & \text { Comprehensive Emergency Obstetric Care } \\ \text { CS } & \text { Civil Surgeon } \\ \text { DCM } & \text { Drugs, Consumables and Maintenance } \\ \text { DD-FP } & \text { Deputy Director-Family Planning } \\ \text { DGFP } & \text { Directorate General of Family Planning } \\ \text { DGHS } & \text { Directorate General of Health Services } \\ \text { DH } & \text { District Hospital } \\ \text { DPM } & \text { Deputy Program Manager } \\ \text { DSF } & \text { Demand-Side Financing } \\ \text { EmOC } & \text { Emergency Obstetric Care } \\ \text { EPI } & \text { Expanded Program on Immunization } \\ \text { FWV } & \text { Family Welfare Visitor } \\ \text { GOB } & \text { Government of Bangladesh } \\ \text { MLSS } & \text { Member of Lower Subordinate Services } \\ \text { MNCH } & \text { Maternal, Newborn and Child Health } \\ \text { MNH } & \text { Maternal and Neonatal Health } \\ \text { MOHFW } & \text { Ministry of Health and Family Welfare } \\ \text { MO-MCHFP } & \text { Medical Officer-Maternal and Child Health and Family Planning } \\ \text { NGO } & \text { Non-governmental Organization } \\ \text { OGSB } & \text { Obstetrics and Gynecological Society of Bangladesh } \\ \text { P4P } & \text { Pay-for-Performance } \\ \text { PNC } & \text { Postnatal Care } \\ \text { PPH } & \text { Postpartum Hemorrhage } \\ \text { QAG } & \text { Quality Assurance Group } \\ \text { QAT } & \text { Quality Assurance Team } \\ \text { RH } & \text { Reproductive Health } \\ \text { RMO } & \text { Resident Medical Officer } \\ \text { SSN } & \text { Senior Staff Nurse } \\ \text { UFPO } & \text { Upazila Family Planning Officer } \\ \text { UHC } & \text { Upazila Health Complex } \\ \text { UHFPO } & \text { Upazila Health and Family Planning Officer } \\ \text { UNFPA } & \text { United Nations Population Fund } \\ \text { UNICEF } & \text { United Nations Children Fund } \\ & \end{array}$




\section{Executive Summary}

The Population Council proposes a pilot study that will test two innovative service delivery models to provide financial incentives to the facility as a way to enhance performance, and subsidized coupons to the poor clients to increase access and utilization of maternal, newborn and child health $(\mathrm{MNCH})$ services in Bangladesh as part of the Government of Bangladesh (GoB) and United Nations Children's Fund (UNICEF) ongoing $\mathrm{MNCH}$ and maternal and neonatal health $(\mathrm{MNH})$ projects. The proposed study aims to utilize existing projects' intervention components and introduce models to provide financial incentives to the providers as pay-for-performance (P4P), and to the poor pregnant women and mothers of newborn and underfive children in the form of coupons. P4P connotes paying providers incentives in terms of a salary supplement for achieving at least a benchmark of performance measured in terms of both quantity and quality of services.

The first and foremost task of this pilot study is to develop an implementable P4P mechanism and coupon guidelines. To develop the guidelines, workshops with both national and local level program managers and service providers were organized. Under the leadership of Directorate General of Health Services (DGHS), Population Council organized four workshops (one at the national and three at the district level) with financial and technical assistance from UNICEF in April and May 2010. In July, the DGHS replaced Nilphamari with Kurigram district for which the Council organized the fifth workshop in August in Kurigram. Both national and district level workshops followed the same agenda. At the national workshop, a draft guideline was developed for introducing $\mathrm{P} 4 \mathrm{P}$ mechanism in the public sector. Later, the guideline was modified at the district workshops. The mechanism for introducing P4P initiatives into the government health system has been delineated in the guidelines. The P4P mechanism has been sketched out based on the workshop findings.

\section{Study design}

Study location. P4P project will be implemented in three districts. As the study is nested within GOB-UNICEF's existing MNCH/MNH projects, three districts have been purposively selected by UNICEF for intervention. The selected districts are Jamalpur, Gaibandha and Kurigram. Nilphamari was initially selected but the DGHS replaced Nilphamari with Kurigram in July 2010. Thakurgaon has been selected as the control site.

Study sites. From each district, one District Hospital and three Upazila Health Complexes (one with comprehensive emergency obstetric care (EmOC) and two with basic EmOC facilities) will receive the interventions. Thus, a total of 12 units from the three districts will be exposed to interventions. The duration of program interventions will be 12 months.

Study strategies. Two strategies will be tested across study sites. The first strategy will provide cash incentives for both providers and poor clients while the second strategy will provide cash incentive for providers only. Gaibandha and Kurigram districts of the MNCH project have been assigned for strategy 1 while Jamalpur district of MNH project has been selected for strategy 2. 
Along with providing supply-side incentives, the P4P approach will attempt to reduce demandside barriers by offering financial assistance to meet out-of-pocket expenses related to medicine, diagnostics, transportation and other costs to poor women and children. This will help to identify whether P4P approach, with or without the demand-side financing, results in increased utilization of MNCH services.

Beneficiaries. The primary beneficiaries will be poor pregnant women, newborns and under-five children who will have increased accessibility to, availability of and use of quality MNCH care services. Service providers who provide maternal and neonatal services are the secondary beneficiaries.

\section{P4P mechanism}

Based on the deliberations, presentations and discussions made in the workshops, the process and structure to pay incentives to service providers have been outlined. In addition, both quantitative and qualitative indicators for measuring performance of the facility were also determined. The key recommendations regarding the P4P mechanism are:

- Incentives will be provided to motivate service providers at the facility level. Program managers and MNCH service providers at District Hospital and Upazila Health Complex will be entitled to receive incentives. Incentives will also be given to indirect service providers and administrative and support staff. Besides, the coupon distributors for coupon distribution and field workers for successful referral of complicated cases will receive incentives.

- Incentives will be allocated to program managers, service providers and administrative and support staff based on the level of their efforts or their relative performance.

- There should be site-specific performance targets (against defined indicators) for incentives. In determining the benchmark level, last three years performance will be considered. Targets will be set at a standard achievable level.

- One-month or one and a half months' basic salary will be rewarded as performance payment in a quarter if the facility attains first and second levels of performance target, respectively. There will be no negative incentives.

- Program managers and direct service providers will receive full incentive (one-month's basic salary per quarter) while indirect service providers and administrative and support staff will be entitled to half incentive. However, selected support staffs like ward boy, aya, sweeper, stretcher bearer and ambulance driver will receive full incentive. The benefit ratio of the designated persons who will keep record and make payment against coupon and incentives, and distribute medicines will be considered 100. The field workers including Family Welfare Assistants (FWAs), Health Assistants (HA) and NGO workers will receive Taka 50 for each successful MNCH complications related referral case. 
- Quality Assurance Group (QAG) will be formed to accredit the facilities for EmONC services, and to monitor the services for determining the eligibility of the facility to receive incentives. QAG will be formed within the government health system in order to ensure sustainability of quality assurance system. The group will consist of technical persons from the nearby Medical College and District Hospital, and representatives from local professional bodies. It will be formed separately for each facility. The QAGs will accredit the facilities and measure the performance of the facilities at every quarter.

- Quarterly visits by the QAGs cannot ensure quality unless teams from the facilities take lead in ensuring quality and keeping standard MNCH care. Therefore, each facility will have quality assurance teams (QATs) formed for each of the service units with the providers and support staff of the respective facilities. For instance, separate QATs will be formed for emergency room, Operation Theater, labor room, indoor and outdoor services.

- Third party, Population Council will calculate the incentive, based on service statistics and Quality Assurance Group reports, at the end of performance quarter.

- Facility-based P4P committees will be formed at both the district and upazila levels to set the benchmark and performance targets, manage incentive distribution, oversee financial reimbursement and make payment.

- P4P committee will also manage facility-based Drugs, Consumables and Maintenance Fund. A small amount of Drug, Consumables and Maintenance fund will be provided to each P4P Committee to meet the emergency maintenance, and needs for drugs and consumables to maintain the functionality and quality of care.

- Incentive fund will be kept in a bank and there will be separate bank account with each facility. Facility-based P4P committees will operate the respective P4P bank account.

- Payment will be made by issuing account payee checks to providers. Signatories at the upazila level will be UHFPO and RMO, and Civil Surgeon/ Superintendent and RMO at the district level.

- Incentive calculation and payment will be made within 30 days of the end of the quarter.

- The facility-based P4P and/or coupon committee will maintain financial record, prepare financial report and send the report to the Directorate General of Health Services.

- Along with providing the performance incentives, the project will offer financial assistance in the form of coupons to meet out-of-pocket expenses related to medicine, transportation and other costs incurred by poor women and children.

- The beneficiaries of coupons will be the rural residents of the selected upazilas of Kurigram and Gaibandha. They will include- 
- Poor pregnant women;

- Poor mothers of neonates; and

- Poor mothers of under-five children.

- Existing voucher distribution system under the government DSF program will be utilized to identify the poor pregnant women and mothers, and distribute coupons. The distributor will receive Taka 20 for each coupon distribution and orientation to the coupon holders.

- Guidelines will be developed for coupons distribution and utilization. Coupons will cover transportation, medicines/diagnostics, and incidental costs for the poor pregnant women, neonates and under-five children.

- The number of coupons for particular services will be as follows:

- Antenatal care: Four times

- Pregnancy complication: One time

- Delivery care: One time

- Postpartum complications including one follow-up care: Two times

- Neonatal complications including one follow-up care: Two times

- Under-five children complications including one follow-up care: Two times

- Medicines and diagnostics fund will ensure continuous supply of necessary medicines from the facility for coupon recipients and meet emergency expenses for medicines and/or diagnosis.

- Both the distance and types of services will be considered to determine the amount of financial assistance to cover transportation cost. For transportation, clients receiving cesarean section or complications management service from Upazila Health Complex and District Hospital will be given 300-700 taka subject to the distance from client's home to the facility. A maximum of 700 taka has been proposed as transportation cost for clients coming from remote or char areas for cesarean section or complications management service. Clients receiving pre-natal checkups from facility will be given 100 taka for each visit up to four visits for covering transportation cost.

- Regarding incidental cost, it has been proposed that clients, who need hospitalized care, will be given 100 taka per night to cover food for the attendant. The maximum limit of incidental costs will be 500 taka. If the coupon recipient needs to stay longer at the facility for treatment (as advised by the provider), the amount of incidental costs could be increased to the maximum of 1,000 taka. The beneficiaries should get money from respective Upazila Health Complex and District Hospital on the day they receive services or before getting released from the facility. 


\section{Table of Contents}

Acknowledgements iv

Abbreviations v v

Executive Summary vi

$\begin{array}{ll}\text { Background } & 1\end{array}$

Purpose

Organization 2

Presentation of Keynote Paper: The P4P Approach 3

$\begin{array}{lr}\text { Findings from Group Work: Developing P4P Guideline } & 6\end{array}$

Prospects and Challenges of P4P Approach: Stakeholders' Views 16

Way Forward 19

Annexure 1: Program of the Workshop 24

Annexure 2: List of Workshop Participants 29

Annexure 3: Target Beneficiaries and Benefit Ratio 39 


\section{BACKGROUND}

The Government of Bangladesh (GoB) has established an extensive network of health facilities and services to provide maternal and child health services from grassroots to higher levels. Yet, the healthcare infrastructure is to significantly improve skilled delivery at birth, institutional delivery, basic and emergency obstetric care, and newborn complications care. Home is the site of 85 percent of deliveries, where traditional birth attendants with little knowledge and skills are the primary resources.

Improving skilled birth attendance at delivery, and access to facility-based basic and emergency obstetric and newborn care are vital to improve maternal and neonatal health. But, health system in Bangladesh faces a critical challenge on the supply side: unavailability of quality services at public health facilities, which is due to inadequately motivated providers, vacant positions and absenteeism of the providers. On the other hand, the salary of public-sector providers does not depend on the quality of work and the quantity of services provided. In this situation, paying an incentive to the facility based on a performance benchmark achieved by the facility as a whole has the potential to increase the quantity and quality of maternal, neonatal and child health $(\mathrm{MNCH})$ care, provided that the required facility infrastructure including human resources is in place. As observed in many developing countries, incentives given on performance can overcome the supply-side barriers in improving the availability and quality of health care.

Incentive has the potential to entice the service providers to perform to reach the target within the stipulated time. Providing performance payment requires substantial financing for a certain period, but it may be a useful way to reduce maternal and infant mortality for achieving MDGs in Bangladesh.

The Population Council proposes a pilot study that that will test two innovative service delivery models to provide financial incentives to the facility as a way to enhance performance, and subsidized coupons to the poor clients to increase access and utilization of maternal, newborn and child health (MNCH) services as part of GOB-UNICEF's ongoing MNCH/MNH projects.

\section{PURPOSE}

As part of the proposed pay-for-performance (P4P) project, policy workshops were organized to develop an implementable P4P Guideline. Under the leadership of Directorate General of Health Services (DGHS), Population Council in collaboration with James P. Grant School of Public Health, BRAC University, organized five workshops (one at the national and four at the district level), with financial and technical assistance from UNICEF.

A national level workshop was organized on March 31, 2010 in Dhaka, with the purpose to identify possible mechanisms for introducing P4P initiative into the government health system. At the workshop, there was a structured discussion on how to introduce pay-for-performance in the government health sector for increased utilization of $\mathrm{MNCH}$ services in rural areas in Bangladesh. At the national workshop, draft P4P guidelines were developed, which were later shared at the district workshops. 
Workshops were held in four districts. The first district-level workshop was held in Jamalpur on April 8, 2010, the second in Nilphamari on May 2, 2010, the third in Gaibandha on May 3, 2010 and the fourth in Kurigram on August 9, 2010. The purpose of the district workshops was to have a structured discussion on the draft P4P guideline and to receive field-level inputs to make the guideline realistic and implementable.

\section{ORGANIZATION}

This report is the outcome of the five workshops on "Introducing Pay-For-Performance Approach to Increase Utilization of Maternal, Newborn and Child Health Services in Bangladesh.”

All workshops followed the same agenda. The workshops were half-day long and divided into three sessions: Inaugural, Group Work, and Concluding (Annexure-1).

At the national workshop, Professor Shah Monir Hossain, Director General, DGHS was scheduled to be present as the Chief Guest. Due to unavoidable circumstances, the Director General could not attend the workshop. Instead, Professor Khandoker Md. Shefayet Ullah, Additional Director General attended and inaugurated the workshop as the Chief Guest. Dr. A.B.M. Jahangir Alam, Director, Primary Health Care and Line Director, Essential Services Delivery, DGHS chaired the workshop. Dr. Md. Anwar Hossain Munshi, Joint Chief, Health Economics Unit, Ministry of Health and Family Welfare (MOHFW) and Dr. Jafar Ahmad Hakim, Director, Maternal and Child Health Services and Line Director, Maternal ChildReproductive Health, Directorate General of Family Planning were special guests at this workshop.

In the first session of the national workshop, Dr. Ubaidur Rob, Country Director, Population Council, Bangladesh and Dr. Lubana Ahmed, Health Specialist, UNICEF/Bangladesh jointly presented the keynote paper. The second session was dedicated to group discussion. Three groups were formed and given specific topics to compile their understanding on those issues. In the concluding session, three groups presented their recommendations on the issues assigned to them. After an interactive discussion, chair and special guests of the workshop provided important directions to introduce P4P for MNCH services in Bangladesh.

A total of 94 participants attended the national workshop. Participants were primarily from the Directorate General of Health Services and the Health Economics Unit of MOHFW. Participants from other public organizations like National Institute of Population Research and Training (NIPORT) and National Institute for Preventive and Social Medicine (NIPSOM) joined the workshop. Civil Surgeons from three selected districts participated at the workshop as well. In addition, representatives from selected development partners and professional institutions attended the workshop (Annexure-2).

In the three district workshops, Dr. A.B.M. Jahangir Alam attended as the Chief Guest and Dr. Kazi Md. Habibur Rahman, Program Manager, Reproductive Health, DGHS as the Special Guest. In two district workshops, Dr. Jafar Ahmad Hakim was present as Special Guest. 
Respective civil surgeons chaired the district level workshops while Deputy Director-Family Planning (DD-FP) welcomed the participants to the events.

The total number of participants at the district workshops ranged from 38 to 60. Managers and relevant service providers from District Hospitals and Upazila Health Complexes were the key participants at the district. Representatives from partner non-governmental organizations (NGOs) also attended the workshops. Among others, representatives from development partners and international organizations were present at the workshops (Annexure-2).

\section{PRESENTATION OF KEYNOTE PAPER: THE P4P APPROACH}

This section summarizes the keynote paper presented in the inaugural session of the workshops. Keynote presentation focused on maternal and child health situation in Bangladesh, barriers to providing quality $\mathrm{MNCH}$ services, human resources for $\mathrm{MNCH}$ services and a proposed $\mathrm{P} 4 \mathrm{P}$ design.

At the outset, Dr. Lubana Ahmed, Health Specialist, UNICEF/Bangladesh provided the background for undertaking the P4P project. Dr. Ahmed described the current MNCH status in Bangladesh. She highlighted on several supply-side challenges in the health sector, such as human resource, quality of care, and logistics and supplies. She said that despite comprehensive infrastructure, health system in Bangladesh faces a critical challenge on human resource. She stated that health system was not able to provide quality services due to sub-optimal performance of providers which was also compounded with the lack of required supplies and logistics.

Dr. Ahmed mentioned several aspects of human resource challenges that exist in the health system in Bangladesh.

- Poor working environment for providers

- Frequent changes at the managerial level

- Low remuneration and lack of performance-based incentive

- Referral of patients to private clinics for personal gain

- Patients have to pay out-of-pocket charges

- Working of 'Gynecology-Obstetrics' consultant of Upazila Health Complex in Medical College Hospital under deputation

- Perceived lack of confidence of emergency obstetric care (EmOC) trained doctors, especially for six-month training recipients.

Dr. Ahmed justified the need to introduce financial motivation for providers as she strongly believed that performance-based payment can motivate additional efforts, encourage compliance with recommended clinical practice, and inspire innovation in service delivery to reach underserved populations. Moreover, financial incentive is likely to inspire changes in behavior among providers. Dr. Ahmed referred to several global experiences with the performance-based financial incentives that contributed to improved performance of providers. 
While discussing the prospect of introducing performance-based financial incentives in the health sector in Bangladesh, Dr. Ahmed referred to the incentive provided under the family planning and demand-side financing programs. Family planning program provides incentives to providers in promoting long-acting and permanent methods. She also elaborated on demand-side financing for maternal health which allows incentive payment on case basis to providers.

Dr. Ahmed mentioned the current UNICEF activities directed towards improving MNCH. UNICEF with the GOB and NGO partners has been implementing two MNCH/MNH projects in eight districts, where UNICEF provides technical assistance in enhancing capacity of the providers and strengthening facilities, and BRAC/CARE increases demand for services and strengthens capacity of community-based providers. She strongly felt the necessity to introduce $\mathrm{P} 4 \mathrm{P}$ for motivating service providers to improve the quantity as well as the quality $\mathrm{MNCH}$ services in the existing $\mathrm{MNCH} / \mathrm{MNH}$ programs.

Dr. Ubaidur Rob, Country Director, Population Council elaborated on the P4P study design. He said that the Population Council developed a P4P approach based on stakeholder analysis (workshop findings and utilizing the available literature on demand-side financing schemes in Bangladesh). He informed that upon request from UNICEF, the Council developed a proposal to introduce P4P for MNCH services in the GOB-UNICEF's ongoing MNCH/MNH projects. The proposed study will utilize existing $\mathrm{MNCH}$ project intervention components and introduce "payfor-performance” model, that is, paying providers a salary supplement for achieving at least a benchmark of performance in terms of increased quantity as well as quality of services delivered.

Regarding study location, Dr. Rob informed that the P4P project will be implemented in three districts. He clarified that as the study will be nested within GOB-UNICEF's existing $\mathrm{MNCH} / \mathrm{MNH}$ projects, three districts have been purposively selected by UNICEF for intervention. The selected districts are Jamalpur, Gaibandha and Nilphamari (Nilphamari was later on replaced with Kurgram). From each district, one District Hospital and three Upazila Health Complexes (UHCs) will receive the interventions. Among three intervention UHCs, one UHC with comprehensive emergency obstetric care and two UHCs with basic emergency obstetric care will be selected. A total of 12 units from 3 districts will be exposed to interventions. Thakurgaon, which is similar to the intervention districts, has been selected as the control site. The experimental groups will receive the program interventions for 12 months.

While discussing strategies of the P4P study, Dr. Rob said that two strategies will be tested across study sites. The first strategy will introduce a P4P scheme for motivating service providers to improve the quantity as well as the quality of services and will enable poor pregnant women, and mothers of newborns and under-five children to access services by reducing their out-of-pocket costs. The second strategy will constitute a P4P scheme for providers only. Thus, the first strategy will provide cash incentive for both providers and poor clients while the second strategy will provide cash incentive for providers only. Two out of three districts will be randomly assigned for strategy 1 while the remaining district will be assigned for strategy 2 .

Dr. Rob explained that along with providing supply-side incentives, the P4P approach will attempt to reduce demand-side barriers by offering financial assistance to meet out-of-pocket expenses related to medicine, transportation and other costs to poor women and children. This 
will help to identify whether P4P approach, with or without the demand-side financing, results in increased utilization of MNCH services.

Dr. Rob briefly discussed the project objective and beneficiaries. He stated the long-term goal of the project is to improve maternal, newborn and child health, particularly to reduce maternal, neonatal and under-five child mortality and morbidity. The immediate objective of the study is to test and compare two service delivery models to increase the utilization of maternal and neonatal care services, and under-five children's life-threatening health care services from the facilities.

The primary beneficiaries will be poor pregnant women, newborns and under-five children who will have increased accessibility to, availability of and use of quality $\mathrm{MNCH}$ care services. A set of poor selection criteria will be used in consultation with GOB, BRAC and CARE. Service providers who provide maternal and neonatal services are the secondary beneficiaries. He described the process and structure to pay incentives to service providers as a part of the study design. In particular, he highlighted the prospective recipients, payment rules and management of the P4P mechanism.

Dr. Rob proposed that incentives can be provided to motivate service providers at the facility level. MNCH providers at District Hospital and Upazila Health Complex will be entitled to receive incentives. Incentives will also be given to program managers and administrative and support staff as a way to improve outcomes. He also sketched out a plan how the incentive can be determined. Setting the performance target for incentive will be the first step. Dr. Rob emphasized that while determining the incentives, it will be considered that service providers can earn at least one-month basic salary as performance payment in a quarter if the facility attains the performance targets. There will be no negative incentives.

Dr. Rob pointed out an important issue regarding payment rules that service provider teams and administrative and support staff should not receive equal amount of incentives, rather incentives should be distributed among the concerned staff based on the level of their efforts. He cited an example that if the direct MNCH service providers receive 100 percent of their one-month basic salary in a quarter as incentive, the indirect $\mathrm{MNCH}$ service providers and administrative staff will receive 50 percent of their basic salary as incentive.

Regarding measurement of performance, Dr. Rob mentioned using service statistics and Quality Assurance Groups' reports. A systematic financial reimbursement system will be employed for calculating and verifying invectives. Third party, the Population Council will calculate the incentive and payment will be made through checks.

Dr. Rob emphasized the need to ensure two prerequisites before introducing P4P. The first and foremost prerequisite for implementing P4P approach is that health facilities remain functional with necessary structure, supplies and trained providers. The second prerequisite is to have an inbuilt 'quality assurance system' for accrediting the facilities that provide minimum acceptable level of MNCH care and ensuring routine measurement of performance. Dr. Rob concluded by reiterating that it will not be possible to distribute incentive unless the facility achieves the performance targets, which largely depends on the availability of providers and facility readiness. 


\section{FINDINGS FROM GROUP WORK：DEVELOPING P4P GUIDELINE}

In consultation with both the national and local level program managers and service providers, P4P guidelines were developed, which was done at two stages. In the first stage, three draft guidelines on P4P mechanism were prepared at the national workshop:

- Indicators and performance measurement

- Beneficiaries, benefit ratio and payment rules, and

- Reimbursement mechanism.

Based on the suggestions from the district workshops, these guidelines were modified. The following discussion highlights the major points made in group presentation. Group presentations were followed by an open discussion.

\section{A. Indicators and Performance Measurement}

On the basis of the draft P4P outline developed at the national workshop, participants at the district workshops determined both quantitative and qualitative indicators for measuring performance of the facility.

Quantitative indicators have been selected based on the types of services. Program managers and service providers identified 11 indicators for pregnancy, delivery and post-partum services. They stated that there are few maternal health indicators which cannot be measured for Basic Emergency Obstetric Care (BEmOC) UHC: cesarean section, ante-partum hemorrhage, and postpartum hemorrhage (Table 1).

Five indicators were identified for newborn care, and three indicators for children's severe case management. Phototherapy for neonatal jaundice are offered from the District Hospital, hence these indicators will not be measured at the Upazila Health Complex. Similarly, severe

malnutrition is treated at the District Hospital for which this indicator applies for the District Hospital alone (Table 1). 
Table 1 List of Quantitative Indicators for Performance Measurement

\begin{tabular}{|c|c|c|c|}
\hline Quantitative indicators & DH & $\begin{array}{l}\text { CEmOC } \\
\text { UHC }\end{array}$ & $\begin{array}{l}\text { BEmOC } \\
\text { UHC }\end{array}$ \\
\hline \multicolumn{4}{|l|}{ Antenatal care } \\
\hline Antenatal care & $\sqrt{ }$ & $\sqrt{ }$ & $\sqrt{ }$ \\
\hline \multicolumn{4}{|l|}{ Institutional Delivery } \\
\hline Normal delivery & $\sqrt{ }$ & $\sqrt{ }$ & $\sqrt{ }$ \\
\hline $\begin{array}{l}\text { Assisted vaginal delivery } \\
\text { (vacuum extraction, forceps) }\end{array}$ & $\sqrt{ }$ & $\sqrt{ }$ & $\sqrt{ }$ \\
\hline Cesarean section & $\sqrt{ }$ & $\sqrt{ }$ & - \\
\hline \multicolumn{4}{|l|}{ Delivery complications management } \\
\hline $\begin{array}{l}\text { Removal of retained placenta/ dilation and } \\
\text { curettage }\end{array}$ & $\sqrt{ }$ & $\sqrt{ }$ & $\sqrt{ }$ \\
\hline Ante-partum hemorrhage & $\sqrt{ }$ & $\sqrt{ }$ & - \\
\hline Postpartum hemorrhage & $\sqrt{ }$ & $\sqrt{ }$ & - \\
\hline Pre-eclampsia management & $\sqrt{ }$ & $\sqrt{ }$ & $\sqrt{ }$ \\
\hline Eclampsia management & $\sqrt{ }$ & $\sqrt{ }$ & $\sqrt{ }$ \\
\hline Other operations & $\sqrt{ }$ & $\sqrt{ }$ & - \\
\hline \multicolumn{4}{|l|}{ Postnatal care } \\
\hline PNC within 24 hours & $\sqrt{ }$ & $\sqrt{ }$ & $\sqrt{ }$ \\
\hline PNC within 42 days & $\sqrt{ }$ & $\sqrt{ }$ & $\sqrt{ }$ \\
\hline \multicolumn{4}{|l|}{ Newborn care } \\
\hline Low birth weight with appropriate referral linkage & $\sqrt{ }$ & $\sqrt{ }$ & $\sqrt{ }$ \\
\hline Asphyxia management & $\sqrt{ }$ & $\sqrt{ }$ & $\sqrt{ }$ \\
\hline Sepsis management & $\sqrt{ }$ & $\sqrt{ }$ & - \\
\hline Neonatal resuscitation with ambu-bag & $\sqrt{ }$ & $\sqrt{ }$ & $\sqrt{ }$ \\
\hline Phototherapy for neonatal jaundice & $\sqrt{ }$ & - & - \\
\hline \multicolumn{4}{|l|}{ Under-5 children's severe case management } \\
\hline Severe diarrhea management & $\sqrt{ }$ & $\sqrt{ }$ & $\sqrt{ }$ \\
\hline Pneumonia management & $\sqrt{ }$ & $\sqrt{ }$ & $\sqrt{ }$ \\
\hline Severe malnutrition treatment & $\sqrt{ }$ & $\sqrt{ }$ & - \\
\hline Other severe diseases management & $\sqrt{ }$ & $\sqrt{ }$ & $\sqrt{ }$ \\
\hline
\end{tabular}

All participants suggested a third party, which will measure these quantitative indictors. It was advised that service statistics will be regularly collected for measuring those indicators. 
Qualitative indicators have been developed on physical readiness of the facility, compliance with the service protocol and ethical issues for client satisfaction. Through the workshops, eight qualitative indicators were determined for assessing the compliance with the service protocol. Seven indicators can be measured at all levels. As there is no provision for blood screening at the BEmOC UHC, 'utilization of blood screening before transfusion' will be measured at the District Hospital and Comprehensive Emergency Obstetric Care (CEmOC) UHC. Key qualitative performance indicators for emergency obstetric care facilities are shown in Table 2.

Table 2 List of Qualitative Indicators for Performance Measurement

\begin{tabular}{lccc}
\hline Qualitative indicators & DH & $\begin{array}{c}\text { CEmOC } \\
\text { UHC }\end{array}$ & $\begin{array}{c}\text { BEmOC } \\
\text { UHC }\end{array}$ \\
\hline Use of partograph & $\sqrt{ }$ & $\sqrt{ }$ & $\sqrt{ }$ \\
Use of oxytocin for PPH & $\sqrt{ }$ & $\sqrt{ }$ & $\sqrt{ }$ \\
Use of MgSO $_{4}$ for eclampsia & $\sqrt{ }$ & & $\sqrt{ }$ \\
Use of parenteral antibiotics for controlling & $\sqrt{ }$ & $\sqrt{ }$ \\
infection of mother and child & & $\sqrt{ }$ & - \\
Active Management of Third Stage Labor & $\sqrt{ }$ & $\sqrt{ }$ \\
(AMTSL) [Use of oxytocin, cord traction and & & $\sqrt{ }$ & $\sqrt{ }$ \\
uterine massage] & $\sqrt{ }$ & $\sqrt{ }$ \\
Utilization of blood screening before transfusion & $\sqrt{ }$ & & \\
Compliance with EmOC service protocol & & & \\
Compliance with IMCI service protocol & & &
\end{tabular}

Client's reported satisfaction with services can be considered as an important indicator of the quality of services received. Participants identified four indicators which should be considered to measure client satisfaction at all levels.

i. Waiting time $<30$ minutes for emergency patients

ii. Availability of prescribed medicines

iii. Availability of diagnostic facility

iv. Procedure for drug administration explained.

Quality of service largely depends on facility's general readiness. Facilities at all levels should have the following:

i. Infection prevention practiced by the providers

ii. Standard protocol for waste management practiced

iii. Clean environment in the operation theatre and labor room

iv. Separate toilets for females with soap and running water

v. Provider availability displayed on board

vi. User fee displayed

vii. Round-the-clock services for emergency obstetric and neonatal care. 
Five indicators were identified to ensure that necessary human resource and supplies are in place.

- Availability of at least one obstetrician, one anesthetist and one paediatrician at CEmOC facility

- Availability of at least one obstetrician and one paediatrician at BEmOC facility

- Availability of at least two trained nurses on IMCI

- Medicine and supplies in the operation theatre and post operative ward

- Medicine and supplies in the general ward.

All participants agreed that there should be site-specific benchmark and performance targets to receive incentive payments. In determining the benchmark level, last three years' performance should be considered. As the use of MNCH services remains at a low level and there is limited possibility of making significant improvement in a short period of time, the participants advised to setting the target at a standard achievable level.

Participants also suggested forming Quality Assurance Group (QAG) to measure the qualitative indicators. QAG will be formed within the government health system in order to ensure sustainability of quality assurance system. QAG will consist of technical persons from nearby Medical College and District Hospital, and representatives from professional bodies. QAGs will be formed separately for three types of facilities: District Hospital, CEmOC UHC, and BEmOC UHC. A total of 12 facility-based QAGs will be formed. It has also been advised that QAG will measure the indicators at every quarter. Proposed members of the QAGs for different facilities are given in Table 3.

Table 3 Proposed Members of the Quality Assurance Group

\begin{tabular}{ll}
\hline Type & Proposed Members \\
\hline District Hospital Quality Assurance Group & - One obstetrician, one anesthetist and one paediatrician \\
& from nearby medical college hospital \\
& - Civil Surgeon/Superintendant of respective District \\
& Hospital \\
& - One representative from Population Council/ JPGSPH \\
& - Local OGSB representative \\
\hline CEmOC UHC Quality Assurance Group & - One obstetrician, one anesthetist and one paediatrician \\
& from respective District Hospital or nearby medical \\
& college hospital \\
& - Upazila Health Family Planning Officer of respective \\
& Upazila Health Complex \\
& - One representative from Population Council/ JPGSPH \\
\hline BEmOC UHC Quality Assurance Group & - One obstetrician and one paediatrician from respective \\
& District Hospital \\
& - Upazila Health Family Planning Officer of respective \\
& Upazila Health Complex \\
& - One representative from Population Council/ JPGSPH \\
\hline
\end{tabular}


Facility-based Death Review Teams are already in place. Death Review Teams will be revitalized with necessary training in carrying out death reviews of facility-based maternal and neonatal deaths, and still births to examine the context of service, service gaps, and reasons for deaths. Reports prepared by the Death Review Teams will be reviewed for assessing the quality of MNCH services provided by the facility.

\section{B. Beneficiaries, Benefit Ratio, and Payment Rules}

Participants from all four workshops agreed that incentives should be paid quarterly, they, however, differed in terms of the amount of benefit. One-month basic salary per quarter was considered insufficient by most participants in Gaibandha and some participants in national workshop. Some claimed one-month basic salary per month instead of per quarter, thus in the defined performance period a total of three months' basic salary should be given. In doing so, it will require a mammoth investment, for which it may not be sustainable. Eventually, it has been accorded that one-month basic salary per quarter will be rewarded as performance incentive.

There will be two levels of performance incentives. Facility-wise two levels of targets will be set in consultation with respective QAG and P4P committee. The service providers will be able to earn one-month basic salary as performance payment in a quarter if the facility attains first level of target. In case of achieving second level of targets, the providers will receive one and a half months basic salary as performance payment in a quarter.

Participants identified target beneficiaries, their level of effort and the benefit ratio. Incentives will be provided to motivate service providers at the facility level. There has been a concurrence of opinions as observed at all the workshops that incentive beneficiaries will include managers, direct service providers, indirect service providers and administrative and support staff. A list of proposed beneficiaries with appropriate benefit ratio has been prepared during group discussion (see Annexure). As incentives will be for the service provider teams as well as for administrative and support staff, the participants did not differ with the perception that incentives payable to the facility will be distributed among the concerned staff based on the level of their efforts.

Participants stated that Civil Surgeon/Superintendent deserves to be incentive recipient since the performance of the District Hospital is subject to their leadership, management and supervision. Similarly, incentive to the DD-FP has the potential to achieve the improved performance in family planning services, as acknowledged by the workshop participants.

At the District Hospital, providers who will be entitled to receive incentives for maternal and child health services include:

i. Senior Consultant (Gynecology \& Obstetrics)

ii. Senior Consultant (Pediatrics)

iii. $\quad$ Resident Medical Officer (RMO)

iv. Junior Consultant (Gynecology \& Obstetrics)

v. Junior Consultant (Anesthesia)

vi. Medical Officer (Anesthesia)

vii. $\quad$ Assistant Register (Gynecology \& Pediatrics) 
viii. Emergency Medical Officer

ix. $\quad$ Medical Officer (Gynecology \& Pediatrics)

x. Medical Officer (Blood Bank)

xi. Senior Staff Nurse

Participants identified Consultant (Radiology), Consultant (Pathology), Medical Technologist (Lab), Medical Technologist (Blood Bank), Medical Technologist (Radiography) and Pharmacist as the indirect providers for MNCH services at the District Hospital.

All agreed to provide incentives to administrative and support staff for ensuring teamwork as a way to improve outcomes. Participants identified five administrative staffs at the District Hospital who will be entitled to receive performance incentives. They are: Deputy Nursing Superintendent/ Nursing Supervisor, Head Assistant-cum-Accountant, Statistician, Store Keeper and MLSS. Workshop participants also mentioned that ward boy, aya, cook/mashalchi, sweeper, security guard, stretcher bearer and ambulance driver provide necessary support services for which they deserve incentives if provided to the facility.

At the workshops, participants prudently used their experience and wisdom in determining the amount of incentives. They came with the proposition that incentives will be allocated to service providers and administrative/management staff on the basis of their relative performance. It emerged from the group discussion that program managers and direct service providers will receive full incentive (equals to one-month basic salary per quarter) while indirect service providers and administrative staff will be entitled to half incentive. Participants were divided in terms of determining the amount of incentives for support staff. Among the support staff, full incentive will be given to ward boy, aya, sweeper, stretcher bearer and ambulance driver while half incentive to cook/mashalchi and security guard.

Similarly, target beneficiaries for the Upazila Health Complex have been identified and their benefit ratio has been determined at the workshops (see Annexure). Upazila Health Family Planning Officer (UHFPO) and Upazila Family Planning Officer (UFPO)/Assistant Upazila Family Planning Officer (AUFPO) will be automatically entitled to incentives as being managers of health and family planning departments of Upazila Health Complex.

At the Upazila Health Complex, the group under the health department that will receive incentives for MNCH services consists of Junior Consultant (Gynecology and Obstetrics), Junior Consultant (Pediatrics), Junior Consultant (Anesthesia) or Medical Officer (Anesthesia), Resident Medical Officer, Medical Officer, Senior Staff Nurse, and Medical Assistant. Under the family planning department, the provider team consists of Medical Officer (MCH-FP) and senior Family Welfare Visitor (FWV).

Participants identified indirect providers for $\mathrm{MNCH}$ services at Upazila Health Complex as Pathologist, Medical Technologist (Radiography), Medical Technologist (Lab), EPI Technician, and Pharmacist. There are four administrative staffs at the Upazila Health Complex who will be entitled to receive performance incentives: Head Assistant-cum-Accountant, Statistician, Store Keeper, and MLSS. For providing necessary support services, ward boy, aya, cook/mashalchi, sweeper, security guard and ambulance driver will also receive incentives. 
Benefit ratio for direct service providers, indirect service providers and administrative staff of Upazila Health Complex will be the same as that of District Hospital. However, allocation of benefit ratio among support staff of Upazila Health Complex will be different from that of District Hospital. Full incentive has been proposed for ward boy, aya, sweeper and ambulance driver while half incentive for cook/mashalchi and security guard.

\section{C1. Reimbursement Mechanism}

Implementation of $\mathrm{P} 4 \mathrm{P}$ approach largely relies on the financial reimbursement system. There was a guided discussion on how to manage financial reimbursement. Participants advised forming P4P implementing committees at both the district and upazila levels to set the benchmark and performance targets, monitor incentive distribution, oversee financial reimbursement and make payment. A consensus has been made that signing and disbursing of the money will remain with the $\mathrm{P} 4 \mathrm{P}$ committees. P4P committee will also manage facility-based Drugs, Consumables and Maintenance (DCM) fund. Each facility will receive certain amount of money during the intervention period for meeting emergency expenses for medicines, consumables and facility maintenance.

Participants sketched out the composition of P4P committees. The members of Upazila P4P committee will include:

- Chairperson - UHFPO

- Member-secretary - RMO

- Members -UFPO/AUFPO, NGO representative (BRAC/CARE), and Upazila Parishad representative.

District P4P committee will have Civil Surgeon/Superintendant as the chair, and RMO as the member-secretary. The other members of the committee will include: DD-FP/Assistant Director -Clinical Contraception, nursing supervisor, NGO representative (BRAC/CARE), and local BMA representative.

Participants also determined how the incentive fund will be operated with no marked variation between workshops. Incentive fund will be kept in a bank and there will be a separate bank account with each facility. For District Hospital, Civil Surgeon/Superintendent will operate the P4P bank account and UHFPO for UHC. Payment will be made in checks to providers. It has been proposed that signatories at the upazila level will be UHFPO and RMO, and Civil Surgeon/Superintendent and RMO at the district level.

There has been consistency in the decisions of all workshops regarding the mode of performance measurement. Performance of facilities will be determined on quarterly basis. Third party will calculate the incentive, based on service statistics and Quality Assurance Group reports. Third party will be an independent body. Facility itself will verify the calculation of incentives made by the third party. Participants emphasized the need to calculate and pay the incentives within the shortest possible time in a way to keep the momentum of the performance up. It has been proposed that incentive calculation and payment will be made within 30 days of the end of the quarter. 
Facility head (Civil Surgeon/Superintendant for District Hospital and UHFPO for Upazila Health Complex) will maintain financial record, prepare financial report and send the report to the DGHS.

\section{C2. Coupon beneficiaries and distribution mechanism}

During the national workshop it has been decided that Nilphamari (presently Kurigram) and Gaibandha will receive both $\mathrm{P} 4 \mathrm{P}$ and demand-side financing interventions. Along with providing the performance incentives, financial assistance in the form of coupons will be provided to meet out-of-pocket expenses. The district workshops discussed the possible mechanism regarding coupon beneficiaries and distribution. The following discussion highlights the key strategies identified through the group work on coupon beneficiaries and distribution mechanism.

Participants identified medicine and transport related costs as major barriers in receiving services from the facilities. In addition, there are some incidental costs, e.g., food for attendant and attendance for child care, for which the poor are not likely to visit the facility for pregnancy, newborn and child care services. Participants were supportive of the idea to offer financial assistance in the form of coupons to meet out-of-pocket expenses related to medicine, transportation and other costs incurred by poor women and children. The beneficiaries of coupons, as suggested by the participants, will include:

- Poor pregnant women

- Poor mothers of neonates; and

- Poor mothers of under-five children.

The process of identification of the poor pregnant women and their verification were also discussed. Participants proposed that government fieldworkers will identify the poor pregnant women and mothers with the standard criteria being used in the government's demand-side financing (DSF) program. NGO health workers can provide assistance if necessary. The respective Union Parishad chairman, female ward-members or existing community group members will verify the list of poor women in a meeting. Government field workers will distribute the coupon among the poor women. NGO health workers can provide assistance if necessary. The field workers will receive Taka 20 for each coupon distribution and orientation. Besides, they will receive Taka 50 per case for successfully referring the MNCH complicated cases.

In order to select poor women for voucher benefit, the government's DSF program uses the following criteria-

- Family income less than 2,500 taka per month

- Land ownership less than 0.15 acre

- Have no income generating assets, e.g., poultry, dairy, orchard, rickshaw, van and similar things.

Considering inflation, the ceiling of Taka 2,500 monthly income has been suggested to be raised to Taka 4,000 only.

The participants determined the number of coupons for particular services. It has emerged from the discussion of the workshops that mothers will get benefit for 
- Antenatal care: Four times

- Pregnancy complication management: One time

- Delivery care: One time

- Postpartum complications management including one follow-up service: Two times

- Neonatal complications management including one follow-up service: Two times

- Under-five children including one follow-up service: Two times.

The P4P committee will acquire necessary medicines for coupon recipients if not available from the government system. By using medicine coupon, the poor pregnant women or mothers of neonates or under-five children will collect the prescribed medicines from the facility. If a poor woman needs necessary investigations, which are not offered at the facility, the P4P committee may utilize Medicines/Diagnostics fund to bear the expenses of such diagnosis on case to case basis.

Participants also discussed the modality of financial assistance for transportation and incidental cost. Transportation cost will be offered for four antenatal care visits, pregnancy complication management, delivery care, postpartum complications management, and complications management for newborns and under-five children. Participants requested policymakers and program managers to be cautious in determining the transportation cost. They underscored the need to consider both the distance and types of services to determine the amount of financial assistance to cover transportation cost. Naturally, the cost of transportation from residence to upazila will be less than that from residence to district. Similarly, transportation cost for routine check-up will differ from that of emergency obstetric care.

For transportation, clients receiving cesarean section or complications management service from Upazila Health Complex and District Hospital will be given 300-700 taka subject to the distance from client's home to the facility. Seven hundred taka has been proposed as transportation cost for clients coming from remote or char areas for cesarean section or complications management service. Clients receiving pre-natal checkups from facility will be given 100 taka for each visit up to four visits for covering transportation cost. Regarding incidental cost, it has been proposed that clients, who need hospitalized care, will be given 100 taka per night to cover food for the attendant. Generally, the maximum limit of incidental costs will be 500 taka. If the coupon recipient needs to stay longer duration at the facility for treatment (as advised by the provider), the amount of incidental costs may be increased to the maximum of 1,000 taka. The beneficiaries should get money from respective Upazila Health Complex and District Hospital on the day they receive services or before the release from the facility.

A small amount of money for Drugs, Consumables, and Maintenance (DCM) will be provided to all the P4P Committees. Facility-based P4P committee will maintain the respective DCM fund, including procurement, distribution and management of drugs, consumables, and emergency expenses for facility maintenance. Facility-based DCM fund will ensure continuous supply of consumables and maintenance to ensure the functionality of the facilities and quality of care. 


\section{Discussion}

Group presentation at the national workshop was followed by both comments and suggestions. On incentive beneficiaries, benefit ratio and payment rule, Dr. A.M. Zakir Hussain, Senior Consultant and Team Leader, Project Preparation Cell of MOHFW provided some suggestions for determining incentive beneficiaries and designing payment rule. Dr. Hussain raised the point of including staffs who will not be directly involved not even remotely involved. He explained the potential risk of giving performance benefit to providers without appropriate classification. If any provider gets incentive without notable contribution, it will create a sense of indignation among the eligible providers, who in turn may lose their enthusiasm and provide marginal level of services to make them enable to get incentives. Dr. Hussain advised the authority to give incentive to providers according to their contribution.

Similarly, Dr. Atef El Maghraby, MNH Project Coordinator, UNFPA provided important directions on the eligibility for incentives. Dr. Maghraby suggested using a mix of guideline/framework and decentralized decision-making in determining the provider's performance and appropriateness for incentive. First, a framework on certain indicators on performance and standards must be developed for incentivizing the provider team or the facility. Then, this framework will be shared with the managers at the upazila or district levels (UHFPO or Civil Surgeon) who know their colleagues' responsibilities more precisely than program managers at the national level.

On reimbursement mechanism, an interactive discussion was held between Dr. A.M. Zakir Hussain and Dr. Abdus Salam Khan, National Coordinator-DSF, World Health Organization at the national workshop. Dr. Hussain wanted to know the justification of number of committees proposed for P4P project and their sustainability. He cautioned against the risk of creating too many committees as it will generate confusion among committees regarding their authority, power and hierarchy. He advised to form limited number of committees and bring relevant professionals for those committees.

In response to query related to the number of committees, Dr. Abdus Salam Khan stated the purpose for proposing those committees, where each committee has separate power and activities. Dr. Khan suggested forming P4P committees at both district and upazila levels. To monitor and manage incentive distribution and reimbursement mechanism at the upazila level, P4P committee will be formed where the task of signing and disbursing of the money will remain with UHFPO and RMO. Dr. Khan reasoned that the committee will be sustainable since UHFPO and RMO must always be in Upazila Health Complex. At the district level, Dr. Khan proposed to modify the existing 'hospital management committee' or reduce its size with the relevant persons to form the District P4P Committee to monitor and manage reimbursement mechanism. He urged the program managers to provide suggestions on the composition of the District P4P Committee. Dr. Khan mentioned the necessity of forming quality assurance group, which will accredit the facilities by assessing their readiness to provide EmOC services, and will monitor the services in a way to determine the eligibility of the providers to receive incentives. He provided a preliminary idea about the composition of the quality assurance committee, where the technical persons from higher-level health facilities, and representatives from professional body, 
development partner and the implementing agency will be incorporated. In addition, as Dr. Khan elaborated, there will be a third party for the calculation of performance benefits.

In reply to Dr. Hussain's concerns regarding sustainability, Dr. Khan stated that the separation of power and authority among the committees will make it sustainable and accountable. But to enhance accountability, proper activation of committees and active involvement of the individuals are required.

Dr. Hussain provided an outline on the third party mechanism for performance measurement. In his opinion, the third party will record both qualitative and quantitative performance, score performance, evaluate the score, and submit it to P4P committee for incentive disbursement. P4P committee will issue the checks against the benefits as calculated by the third party. However, Dr. Hussain expressed his concerns that there would be conflict of interests if UHFPO and RMO were the benefit issuing authority and beneficiary at the same time.

Dr. Khan clarified Dr. Hussain's concern regarding conflict of interest issues related to UHFPO and RMO. He told that UHFPO and RMO will only issue checks. Third party will calculate incentives and handover the performance report to the P4P committee, which will disburse fund as advised by the third party. Third party will be an independent body, and in the pilot phase Population Council will act as the third party.

\section{PROSPECTS AND CHALLENGES OF P4P APPROACH: STAKEHOLDERS' VIEWS}

Low remuneration compared to private sector along with the absence of incentive is the demotivating factor for the public-sector service providers to perform at the optimum level. Incentive is viewed as a missing characteristic for health resources development in Bangladesh. Paying an incentive for achieving the pre-determined target to providers has potential to increase their performance. The government policymakers and program managers appreciated the P4P approach for human resource innovation, and provided important directions on how to implement performance-based financial incentives.

\section{Incorporating Family Planning Department}

Dr. Jafar Ahmad Hakim, Director, Maternal and Child Health Services and Line Director, Maternal Child-Reproductive Health Services, Directorate General of Family Planning was present as Special Guest at the national and two district workshops.

Dr. Hakim informed that performance incentive is a new concept for maternal health, but it was introduced in the Family Planning Program in early 1980s. He appreciated the idea of introducing performance incentives for MNCH services. He noted a key difference between DSF and P4P. Under DSF program incentive is given against performed activities while under P4P program incentive will be given after achieving the preset performance targets.

Dr. Hakim mentioned government's commitment to improving human resources for maternal and child health services by elaborating on 'skilled birth attendant' program, midwifery training 
for female paramedics, and countrywide EmOC training for doctors, nurses and female paramedics.

Dr. Hakim underscored the necessity to include Maternal and Child Welfare Center in the proposed P4P pilot project. He expressed mixed opinions regarding the amount of proposed incentive. He was concerned that the amount of incentive might not be sufficient to bring changes. Conversely, he was in favor of keeping the incentive at a moderate level in a way to enable the government to scale up the project nationally if successful. Dr. Hakim looks ahead for a concerted action to make the P4P initiative successful.

\section{Mobilization of human resource}

Dr. Kazi Habibur Rahman, Program Manager, Reproductive Health, DGHS was present as Special Guest at the district workshops. Dr. Rahman started his speech by providing an overview on government achievements in the health and population sector. He acknowledged reducing maternal and neonatal mortality as two major concerns over health development. Dr. Rahman stressed the need to provide proper antenatal care which he believed as an important step for reducing the risk of maternal deaths.

Dr. Rahman mentioned several structural problems that the government needs to overcome to improve the health and population situation. He identified human resource issues as matters of immediate concern for providing EmOC services. The key problem is the inadequate numbers of EmOC pair. Dr. Rahman recognized the importance of making pair (obstetrician and anesthetist) available in EmOC facilities.

\section{Creating evidence for policy formulation}

Dr. Md. Anwar Hossain Munshi, Joint Chief, Health Economics Unit, MOHFW was present as special guest at the P4P national workshop. Dr. Munshi started his speech by referring to the gap between pledges and implementation of policies or programs, and urged to formulate policy or develop program based on evidence or research. He appreciated the Population Council/UNICEF initiative to create evidence for introducing supply-side financing or pay-for-performance in the health system.

Dr. Munshi was concerned about the potential cost involvement in P4P project, where the beneficiaries will get cash incentives. He expressed concerns that when providers develop the habit of getting benefits for their performance, it will be difficult to keep their performance continued once such benefits are withdrawn. He also raised a pertinent issue regarding the quality of general health care services for which no such incentive is provided. Dr. Munshi insisted on developing an implementable design that will sustain without the assistance of development partners.

Improving service delivery requires necessary supply of human resources. Dr. Munshi reckoned that availability of providers and keeping providers in place would be the most important factor for P4P project. He also advocated including fieldworkers in the P4P benefit package as 
fieldworkers do not have the opportunity to earn more, as service providers earn after office hour.

By referring to the $\mathrm{P} 4 \mathrm{P}$ design which says that financial incentive will be provided based on both quantity and quality of services, Dr. Munshi advised developing an implementable and sustainable mechanism to monitor and measure the providers' performance for incentive.

Finally, Dr. Munshi emphasized the need to develop the P4P model based on what exists in the health system. He was highly optimistic of the P4P pilot project, where outcomes of this project will be incorporated in government policies.

\section{Financial motivation for human resources}

Dr. A.B.M. Jahangir Alam, Director, Primary Health Care and Line Director, Essential Services Delivery, DGHS chaired the national workshop and attended all the district workshops as the Chief Guest.

Dr. Alam's first impression was that the P4P approach presented at the national workshop did not differ much from the MOHFW's DSF program, rather he considered P4P as a modification of DSF program. Nevertheless, Dr. Alam welcomed such initiative through which both mother and child will be benefited.

Dr. Alam cited examples of high remuneration of physicians compared to other professionals in many countries, which he strongly believed as a catalyst for quality and continuous health care services. He also mentioned the examples of 'hardship allowance' which is being given in many countries to providers working in remote or rural areas. By referring to private health sector in Bangladesh, Dr. Alam mentioned the opportunities to earn additional income for health care providers who get incentive on case basis in addition to their salary.

Several features of the P4P approach attracted Dr. Alam's attention. Rewarding incentive to providers based on achieving a performance benchmark for the facility is a commendable initiative as viewed by Dr. Alam. Instead of the individual level as practiced in DSF, incentives will be given to motivate service providers at the facility level. Dr. Alam particularly admired the idea of providing incentive to both direct and indirect providers including administrative and support staff.

Dr. Alam considered that the inclusion of quality as a measurement indicator in P4P approach makes it stand alone from the DSF. Provider performance will be linked with both quantity and quality of services in P4P approach while incentive is given on the basis of individual performance (quantity) in DSF.

Dr. Alam mentioned fieldworkers' importance in making referral to the hospital and raising awareness among pregnant women and their families to visit facilities for services. He shared DSF example where fieldworkers receive incentives upon registering poor pregnant mothers, which can be utilized for the P4P project. 
Dr. Alam recognized the shortage of EmOC pair at the uapzila level, and assured of taking initiatives to provide required service providers for continuous, quality services at the EmOC facilities. Finally, he suggested forming a small group to develop an implementable P4P approach and a $\mathrm{P} 4 \mathrm{P}$ guideline for systematic implementation and management of $\mathrm{P} 4 \mathrm{P}$ mechanism.

\section{WAY FORWARD}

Based on the deliberations, presentations and discussions made in the workshops, the process and structure to pay incentives to service providers have been outlined. The key recommendations regarding the design of $\mathrm{P} 4 \mathrm{P}$ project are:

- The P4P approach will be nested within GOB-UNICEF's existing MNCH/MNH projects. $\mathrm{P} 4 \mathrm{P}$ approach will be tested in the three selected districts.

- From each district, one District Hospital and three Upazila Health Complexes will receive the interventions. Thus, a total of 12 sites from three districts will be exposed to study interventions. Thakurgaon, which is similar to the intervention districts, has been selected as the control site.

- The duration of program interventions will be 12 months.

- Two strategies will be tested across study sites. The first strategy will provide cash incentives for both providers and poor clients while the second strategy will provide cash incentive for providers only. Using two strategies will help to identify whether P4P approach, with or without the demand-side financing, results in increased utilization of MNCH services. Gaibandha and Kurigram districts have been assigned for strategy 1 while Jamalpur district for strategy 2.

- The primary beneficiaries will be poor pregnant women, newborns and under-five children. Service providers who provide maternal, neonatal and child health services are the secondary beneficiaries.

- Incentives will be provided to motivate service providers at the facility level. Program managers and MNCH service providers at District Hospital and Upazila Health Complex will be entitled to receive incentives. Incentives will also be given to indirect service providers and administrative and support staff.

- Incentives will be allocated to program managers, service providers and administrative and support staff based on the level of their efforts or their relative performance.

- One-month basic salary will be rewarded as performance payment in a quarter if the facility attains the first level of performance targets. One and a half months' basic salary will be rewarded as performance payment in a quarter if the facility attains the second level of targets. There will be no negative incentive. 
- Program managers and direct service providers will receive full incentive (one-month's basic salary per quarter) while indirect service providers and administrative and support staff will be entitled to half incentive. However, selected support staffs like ward boy, aya, sweeper, stretcher bearer and ambulance driver will receive full incentive. Note: Level of effort of DD-FP will be $100 \%$ with benefit ratio of 100 . The benefit ratio of the designated persons who will keep record and make payment against coupon and incentives, and distribute medicines will be considered 100. The field workers including FWAs, HAs and NGO workers will receive Taka 50 for each successful MNCH complications related referral case.

- Quality Assurance Group will be formed to accredit the facilities for EmOC services, and to monitor the services for determining the eligibility of the facility to receive incentives. QAG will be formed within the government health system in order to ensure sustainability of quality assurance system. The group will consist of technical persons from nearby Medical College and District Hospital, and representatives from professional bodies. It will be formed separately for three types of facilities: District Hospital, CEmOC UHC, and BEmOC UHC. QAG will measure the qualitative indicators at every quarter.

- Third party, the Population Council, will calculate the incentive, based on service statistics and Quality Assurance Group reports, at the end of performance quarter.

- Each facility will have quality assurance teams QATs formed for each of the service units with the providers and support staff of the respective facilities. For instance, separate QATs will be formed for emergency room, Operation Theater, labor room, indoor and outdoor services. The QATs will meet at least monthly to ensure the quality of care, because the quarterly visits by the QAGs may not ensure the standard quality of care to the pregnant women, neonates and under-five children.

- Facility-based P4P committees will be formed at both the district and upazila levels to set the benchmark and performance targets, mange incentive distribution, oversee financial reimbursement and make payment. P4P committee will also manage facility-based Drugs, Consumables and Maintenance Fund.

- Incentive fund will be kept in a bank and there will be a separate bank account with each facility. Facility-based P4P committees will operate the respective P4P bank account.

- Payment will be made in account payee checks to providers. Signatories at the upazila level will be UHFPO and RMO, and Civil Surgeon/ Superintendent and RMO at the district level.

- Incentive calculation and payment will be made within 30 days of the end of the quarter.

- The facility-based P4P committees will maintain financial record, prepare financial report and send the report to the Directorate General of Health Services. 
- A small amount of Drug, Consumables and Maintenance fund will be provided to each P4P Committee to meet the emergency maintenance, and needs for drugs and consumables to maintain the functionality and quality of care.

- Along with providing the performance incentives, the project will offer financial assistance in the form of coupons to meet out-of-pocket expenses related to medicine, transportation and incidental costs incurred by rural and poor pregnant women, poor mothers of neonates and under-five children.

- The beneficiaries of coupons will be the rural residents of the selected upazilas of Kurigram and Gaibandha. They will include-

- Poor pregnant women;

- Poor mothers of neonates; and

- Poor mothers of under-five children.

- Existing voucher distribution system under the government DSF program will be utilized to identify the poor pregnant women and mothers and to distribute coupons among them.

- The number of coupons for particular services will include:

- Antenatal care: Four times

- Pregnancy complication management: One time

- Delivery care: One time

- Postpartum complications management: Two times

- Neonatal complications management: Two times

- Under-five children: Two times.

- Medicines and diagnostics fund will ensure continuous supply of necessary medicines from the facility for coupon recipients and meet emergency expenses for medicines and/or diagnosis.

- Both the distance and types of services will be considered to determine the amount of financial assistance to cover transportation cost. For transportation, clients receiving cesarean section or complications management service from Upazila Health Complex and District Hospital will be given 300-700 taka subject to the distance from client's home to the facility. A maximum of 700 taka has been proposed as transportation cost for clients coming from remote or char areas for cesarean section or complications management service. Clients receiving pre-natal checkups from facility will be given 100 taka for each visit up to four visits for covering transportation cost.

- Regarding incidental cost, it has been proposed that clients, who need hospitalized care, will be given 100 taka per night to cover food for the attendant. The maximum limit of incidental costs will be 500 taka. If the coupon recipient needs to stay longer duration at the facility for treatment (as advised by the provider), the amount of incidental costs will 
be increased to the maximum of 1,000 taka. The beneficiaries should get money from respective Upazila Health Complex and District Hospital on the day they receive services or before their release from the facility. 
ANNEXURE 


\section{Annexure 1: Program of the Workshops}

\section{National Workshop on}

Introducing Pay-For- Performance (P4P) Approach to

Increase Utilization of Maternal, Newborn and Child Health Services in Bangladesh

BRAC Center Inn, Mohakhali, Dhaka; March 31, 2010

\begin{tabular}{|c|c|}
\hline $9: 00 \mathrm{am}-9: 20 \mathrm{am}$ & Registration \\
\hline Chief Guest: & Prof. Khandoker Md. Shefayet Ullah, Director General, DGHS \\
\hline \multirow[t]{5}{*}{ Special Guests: } & Dr. Md. Anwar Hossain Munshi \\
\hline & Joint Chief (Joint Secretary) Health Economics Unit, MOHFW \\
\hline & Md. Abdul Mannan \\
\hline & Joint Chief, Planning, MOHFW \\
\hline & $\begin{array}{l}\text { Dr. Jafar Ahmad Hakim, Director, MCH Services \& Line Director, MC-RH } \\
\text { Services, DGFP }\end{array}$ \\
\hline Chair: & Dr. A.B.M. Jahangir Alam, Director, PHC \& Line Director, ESD, DGHS \\
\hline $9: 20 \mathrm{am}-9: 25 \mathrm{am}$ & Recitation from the Holy Quran \\
\hline $9: 25 \mathrm{am}-9: 30 \mathrm{am}$ & Welcome Speech \\
\hline \multirow[t]{2}{*}{$9: 30 \mathrm{am}-10: 15 \mathrm{am}$} & $\begin{array}{l}\text { Key Note on Pay-for-Performance Approach for Maternal, Newborn and Child } \\
\text { Healtb Services in public sector: Background, Design and Modalities }\end{array}$ \\
\hline & $\begin{array}{l}\text { - Dr. Ubaidur Rob, Country Director, Population Council } \\
\text { - Dr. Lubana Ahmed, Health Specialist, UNICEF/Bangladesh }\end{array}$ \\
\hline \multirow[t]{2}{*}{ 10:15 am - 11:15 am } & Group Work with Refreshment \\
\hline & $\begin{array}{l}\text { Group A: Indicators and Performance Measurement } \\
\text { Moderator: Dr. S.A.J.M. Musa, Asst. Director, Coordination, DGHS } \\
\text { Group B: Incentive Beneficiaries, Benefit Ratio and Payment Rule } \\
\text { Moderator: Dr. Kazi Md. Habibur Rahman, Program Manager, RH, DGHS } \\
\text { Group C: Reimbursement Mechanism } \\
\text { Moderator: Professor Dr. Sushil Ranjan Howlader, IHE, Dhaka University }\end{array}$ \\
\hline $11: 15 \mathrm{am}-1: 30 \mathrm{pm}$ & Way Forward \\
\hline $11: 15 \mathrm{am}-11: 45 \mathrm{am}$ & Group Presentations \\
\hline $11: 45 \mathrm{am}-12: 15 \mathrm{pm}$ & Discussions \\
\hline $12: 15 \mathrm{pm}-12: 25 \mathrm{pm}$ & Speech by Special Guest: Dr. Jafar Ahmad Hakim \\
\hline $12: 25 \mathrm{pm}-12: 35 \mathrm{pm}$ & Speech by Special Guest: Mr. Md. Abdul Mannan \\
\hline $12: 35 \mathrm{pm}-12: 45 \mathrm{pm}$ & Speech by Special Guest: Dr. Md. Anwar Hossain Munshi \\
\hline $12: 45 \mathrm{pm}-1: 05 \mathrm{pm}$ & Speech by Chief Guest: Prof. Khandoker Md. Shefayet Ullah \\
\hline 01:05 pm - 1:20 pm & Closing Remarks by Chair: Dr. A.B.M. Jahangir Alam \\
\hline $01: 20 \mathrm{pm}-1: 30 \mathrm{pm}$ & Vote of Thanks: Prof. Dr. Anwar Islam, James P. Grant School of Public Health \\
\hline $1: 30 \mathrm{pm}$ & Lunch \\
\hline
\end{tabular}




\section{District Workshop in Jamalpur on}

\section{Introducing Pay-For-Performance (P4P) Approach to}

\section{Increase Utilization of Maternal, Newborn and Child Health Services in Bangladesh}

Conference Room, Civil Surgeon Office, Sadar Hospital, Jamalpur; 8 April 2010

\begin{tabular}{|c|c|}
\hline $9: 30 \mathrm{am}-10: 10 \mathrm{am}$ & Registration \\
\hline Chief Guest: & Dr. A.B.M. Jahangir Alam, Director, PHC \& Line Director, ESD, DGHS \\
\hline Special Guest: & Dr. Kazi Md. Habibur Rahman, Program Manager, Reproductive Health, DGHS \\
\hline Chair: & Dr. Md. Abdul Hakim, Civil Surgeon, Jamalpur \\
\hline 10:00 am - 10:05 am & Recitation from Holy Quran \\
\hline 10:05 am - 10:15 am & Welcome Speech: Dr. Nargis Begum, Deputy Director-Family Planning, Jamalpur \\
\hline 10:15 am - 10:45 am & $\begin{array}{l}\text { Key Note on } \\
\text { P4P for maternal, Newborn and Child Healtb Services: } \\
\text { Design and Mechanism } \\
\quad \text { - Dr. Ubaidur Rob, Country Director, Population Council } \\
\text { - } \quad \text { Dr. Riad Mahmud, Health Officer, UNICEF/Bangladesh }\end{array}$ \\
\hline \multirow[t]{4}{*}{$10: 45 a m-11: 45 a m$} & Group Work with Refreshment \\
\hline & $\begin{array}{l}\text { Group A: Indicators and Performance Measurement } \\
\text { Moderator: Dr. Akhter Jahan, DPM, MNH, DGHS }\end{array}$ \\
\hline & $\begin{array}{l}\text { Group B: Incentive Beneficiaries, Benefit Ratio and Payment Rule E Reimbursement } \\
\text { Mechanism } \\
\text { Moderator: Dr. Azizul Alim, DPM, RH, DGHS }\end{array}$ \\
\hline & $\begin{array}{l}\text { Group C: Coupon Distribution Mechanism } \\
\text { Moderator: Dr. Nazrul Islam, Former Deputy Program Manager, EOC \& DSF, DGHS }\end{array}$ \\
\hline $11: 45 \mathrm{am}-1: 30 \mathrm{pm}$ & Way Forward \\
\hline $11: 45 \mathrm{am}-12: 15 \mathrm{pm}$ & Group Presentation \\
\hline $12: 15 \mathrm{pm}-12: 45 \mathrm{pm}$ & Open Discussion \\
\hline $12: 45 \mathrm{pm}-12: 55 \mathrm{pm}$ & Speech by the Special Guest: Dr. Kazi Habibur Rahman \\
\hline $12: 55 \mathrm{pm}-1: 10 \mathrm{pm}$ & Speech by the Chief Guest: Dr. ABM Jahangir Alam \\
\hline $1: 10 \mathrm{pm}-1: 20 \mathrm{pm}$ & Closing Remarks by the Chair: Dr. Md. Abdul Kakim \\
\hline $1: 20 \mathrm{pm}-1: 30 \mathrm{pm}$ & Vote of Thanks \\
\hline $1: 30 \mathrm{pm}$ & Lunch \\
\hline
\end{tabular}




\section{District Workshop in Nilphamari on}

\section{Introducing Pay-For-Performance (P4P) Approach to \\ Increase Utilization of Maternal, Newborn and Child Health Services in Bangladesh}

Conference Room, Civil Surgeon Office, Sadar Hospital, Nilphamari; 2 May 2010

\begin{tabular}{|c|c|}
\hline $12: 30 \mathrm{pm}-12: 45 \mathrm{pm}$ & Registration \\
\hline $12: 45 \mathrm{pm}-12: 55 \mathrm{pm}$ & Introducing Session \\
\hline Chief Guest: & Dr. A.B.M. Jahangir Alam, Director, PHC \& Line Director, ESD, DGHS \\
\hline Special Guest: & Dr. Jafar Ahmad Hakim, Director, MCH Services \& Line Director, MC-RH Services, DGFP \\
\hline Special Guest: & Dr. Kazi Md. Habibur Rahman, Program Manager, Reproductive Health, DGHS \\
\hline Chair: & Dr. Md. Abdur Rashid Akanda, Civil Surgeon, Nilphamari \\
\hline $12: 55 \mathrm{pm}-1: 00 \mathrm{pm}$ & Recitation from Holy Quran \\
\hline 1:00 pm - 1:10 pm & Welcome Speech: Dr. Md. Ehsanul Haque, AD-CC, Nilphamari \\
\hline 1:100 pm - 1:40 pm & $\begin{array}{l}\text { Key Note on } \\
\text { P4P for maternal, Newborn and Child Health Services: } \\
\text { Design and Mechanism } \\
\quad \text { - Dr. Ubaidur Rob, Country Director, Population Council } \\
\text { - } \quad \text { Dr. Lubana Ahmed, Health Specialist, UNICEF/Bangladesh }\end{array}$ \\
\hline $1: 40 \mathrm{pm}-2: 10 \mathrm{pm}$ & Lunch \\
\hline \multirow{4}{*}{$2: 10 \mathrm{pm}-3: 10 \mathrm{pm}$} & Group Work \\
\hline & $\begin{array}{l}\text { Group A: Indicators and Performance Measurement } \\
\text { Moderator: Dr. Akhter Jahan, DPM, MNH, DGHS }\end{array}$ \\
\hline & $\begin{array}{l}\text { Group B: Incentive Beneficiaries, Benefit Ratio and Payment Rule E Reimbursement } \\
\text { Mechanism } \\
\text { Moderator: Dr. Azizul Alim, DPM, RH, DGHS }\end{array}$ \\
\hline & $\begin{array}{l}\text { Group C: Coupon Distribution Mechanism } \\
\text { Moderator: Dr. Nazrul Islam, Former Deputy Program Manager, EOC \& DSF, DGHS }\end{array}$ \\
\hline $3: 10 \mathrm{pm}-5: 00 \mathrm{pm}$ & Way Forward \\
\hline $3: 10 \mathrm{pm}-3: 40 \mathrm{pm}$ & Group Presentation \\
\hline $3: 40 \mathrm{pm}-4: 10 \mathrm{pm}$ & Open Discussion \\
\hline $4: 10 \mathrm{pm}-4: 20 \mathrm{pm}$ & Speech by the Special Guest: Dr. Kazi Habibur Rahman \\
\hline $4: 20 \mathrm{pm}-4: 30 \mathrm{pm}$ & Speech by the Special Guest: Dr. Jafar Ahmad Hakim \\
\hline $4: 30 \mathrm{pm}-4: 45 \mathrm{pm}$ & Speech by the Chief Guest: Dr. ABM Jahangir Alam \\
\hline $4: 45 \mathrm{pm}-4: 55 \mathrm{pm}$ & Closing Remarks by the Chair: Dr. Md. Abdur Rashid Akanda \\
\hline $4: 55 \mathrm{pm}-5: 00 \mathrm{pm}$ & Vote of Thanks \\
\hline $5: 00 \mathrm{pm}$ & Tea \\
\hline
\end{tabular}




\section{District Workshop in Gaibandha on}

\section{Introducing Pay-For-Performance (P4P) Approach to}

Increase Utilization of Maternal, Newborn and Child Health Services in Bangladesh

Conference Room, Gono Unnayan Kendra, Nashratpur, Gaibandha; 3 May 2010

\begin{tabular}{|c|c|}
\hline $9: 30 \mathrm{am}-10: 00 \mathrm{am}$ & Registration \\
\hline 10:00 am - 10:10 am & Introduction to each other \\
\hline Chief Guest: & Dr. A.B.M. Jahangir Alam, Director, PHC \& Line Director, ESD, DGHS \\
\hline Special Guests: & Dr. Jafar Ahmad Hakim, Director, MCH Services \& Line Director, MC-RH Services, DGFP \\
\hline & Dr. Kazi Md. Habibur Rahman, Program Manager, Reproductive Health, DGHS \\
\hline Chair: & Dr. Md. Rafiqul Islam, Civil Surgeon, Gaibandha \\
\hline 10:10 am - 10:15 am & Recitation from the Holy Quran \\
\hline 10:15 am - 10:25 am & Welcome Speech: Dr. Ferdous Hossain Manju, DD-FP, Gaibandha \\
\hline \multirow[t]{2}{*}{ 10:25 am - 10:55 am } & $\begin{array}{l}\text { Key Note on Pay-for-Performance Approach for Maternal, Newborn and Child Health } \\
\text { Services in Public Sector : Background, Design and Modalities }\end{array}$ \\
\hline & $\begin{array}{l}\text { - Dr. Ubaidur Rob, Country Director, Population Council } \\
\text { - Dr. Lubana Ahmed, Health Specialist, UNICEF/Bangladesh }\end{array}$ \\
\hline \multirow[t]{2}{*}{ 10:55 am - 11:55 am } & Group Work with Refreshment \\
\hline & $\begin{array}{l}\text { Group A: Indicators and Performance Measurement } \\
\text { Moderator: Dr. Md. Khairul Hasan, Health Officer, Maternal Health, UNICEF } \\
\text { Group B: Incentive Beneficiaries, Benefit Ratio and Payment Rule \& Reimbursement } \\
\quad \text { Mechanism } \\
\text { Moderator: Dr. Kazi Md. Habibur Rahman, Program Manager, Reproductive Health, DGHS } \\
\text { Group C: Coupon Distribution Mechanism } \\
\text { Moderator: Dr. Nazrul Islam, Former Deputy Program Manager, EOC \& DSF, DGHS }\end{array}$ \\
\hline $11: 55 \mathrm{am}-1: 45 \mathrm{pm}$ & Way Forward \\
\hline $11: 55 \mathrm{am}-12: 25 \mathrm{pm}$ & Group Presentations \\
\hline $12: 25 \mathrm{pm}-12: 55 \mathrm{pm}$ & Open Discussions \\
\hline $12: 55 \mathrm{pm}-1: 05 \mathrm{pm}$ & Speech by Special Guest: Dr. Kazi Md. Habibur Rahman \\
\hline $1: 05 \mathrm{pm}-1: 15 \mathrm{pm}$ & Speech by Special Guest: Dr. Jafar Ahmad Hakim \\
\hline $1: 15 \mathrm{pm}-1: 30 \mathrm{pm}$ & Speech by Chief Guest: Dr. A.B.M. Jahangir Alam \\
\hline $1: 30 \mathrm{pm}-1: 40 \mathrm{pm}$ & Closing Remarks by Chair: Dr. Md. Rafiqul Islam \\
\hline $1: 40 \mathrm{pm}-1: 45 \mathrm{pm}$ & Vote of Thanks \\
\hline $1: 45 \mathrm{pm}$ & Lunch \\
\hline
\end{tabular}




\section{District Workshop in Kurigram on}

Introducing Pay- For- Performance (P4P) Approach to Increase Utilization of Maternal, Newborn and Child Health Services in Bangladesh

Venue: Doctor's Club, Sadar Hospital, Kurigram; 9 August, 2010

\begin{tabular}{|c|c|}
\hline $10.00 \mathrm{am}-10.30 \mathrm{am}$ & Registration \\
\hline 10:00 am - 10:40 am & Introduction to each other \\
\hline Special Guests: & $\begin{array}{l}\text { Dr. Iqbal Ahmed, DPM, RH, DGHS } \\
\text { Dr. Md. Omar Ali Sankar, DPM } 1^{\text {st }}(\mathrm{ESP}), \text { DGHS }\end{array}$ \\
\hline Chair: & Dr. Md. Golam Mostafa, Civil Surgen, Kurigram \\
\hline $10.40 \mathrm{am}-10.45 \mathrm{am}$ & Recitation from the Holy Quran \\
\hline $10.45 \mathrm{am}-10.55 \mathrm{am}$ & Welcome Speech: Dr. Md. Shamsuddoha, Deputy Director, Family Planning, Kurigram \\
\hline $10.55 \mathrm{am}-11.25 \mathrm{am}$ & $\begin{array}{l}\text { Key Note on Pay-for-Performance Approach for Maternal, Newborn and Child Health } \\
\text { Services in Public Sector : Background, Design and Modalities } \\
\text { - Dr. Ubaidur Rob, Population Council } \\
\text { - Dr. Riad Mahmud, UNICEF, Bangladesh }\end{array}$ \\
\hline $11.25 \mathrm{am}-11.55 \mathrm{pm}$ & Open Discussions \\
\hline $12.30 \mathrm{pm}-12.45 \mathrm{pm}$ & $\begin{array}{l}\text { Speech by Special Guest: Dr. Iqbal Ahmed, DPM, RH, DGHS } \\
\text { Speech by Special Guest: } \\
\text { Dr. Md. Omar Ali Sankar, DPM 1' (ESP), DGHS } \\
\text { Closing Remarks by Chair: Dr. Md Golam Mostafa, Civil Surgeon, Kurigram }\end{array}$ \\
\hline $12.45 \mathrm{pm}-12.50 \mathrm{pm}$ & Vote of Thanks \\
\hline $12.50 \mathrm{pm}$ & Lunch \\
\hline
\end{tabular}




\title{
Annexure 2: List of Workshop Participants
}

\author{
Participant List \\ (Not according to seniority) \\ P4P National Workshop, Dhaka; 31 March 2010
}

1. Professor Khandoker Md. Shefayet Ullah, Additional Director General, DGHS

2. Dr. A.B.M. Jahangir Alam, Director, PHC \& Line Director, ESD, DGHS

3. Dr. Prof. Abul Kalam Azad, Director, MIS, DGHS

4. Dr. A.K.F. Mojibur Rahman, Director, Hospital \& Clinic, DGHS

5. Dr. Kazi Md. Habibur Rahman, Program Manager, Reproductive Health, DGHS

6. Dr. Mosaddeque Ahmed, Program Manager, IMCI, DGHS

7. Dr. Md. Abdul Jalil Mondal, Program Manager, Child Health, DGHS

8. Dr. A.M.N. Zaman, Program Manager, BCC (LCC \& CC), ESD, DGHS

9. Dr. Shamsul Haque, Deputy Director-PHC \& Program Manager-SS, DGHS

10. Dr. A.B.M. Lutful Kabir, Deputy Director, Hospital \& Clinic, DGHS

11. Dr. Md. Shajedul Hasan, Deputy Program Manager, Planning Unit, DGHS

12. Dr. Aminul Hasan, Deputy Program Manager, Training, DGHS

13. Dr. Md. Abu Elias Prodhan, Deputy Program Manager, Quality Assurance, DGHS

14. Dr. Yasmin Rahman, Deputy Program Manager, MCH, Hospital, DGHS

15. Dr. Md. Altaf Hossain, Deputy Program Manager, Neonatal Health, DGHS

16. Dr. Akhtar Jahan, Deputy Program Manager, MNH, RH, DGHS

17. Dr. A. Hannan, Deputy Program Manager, Logistics, PHC, DGHS

18. Dr. Humayun Kabir Khan, Deputy Program Manager, SBA, Reproductive Health, DGHS

19. Dr. Azizul Alim, Deputy Program Manager, EOC, Reproductive Health, DGHS

20. Dr. Md. Mahabubul Alam, Deputy Program Manager, Admin, ESD, DGHS

21. Dr. Rajendra Nath Mehta, Assistant Director, PHC \& DPM, Finance, DGHS

22. Dr. Mamun Parvez, Assistant Director, PHC, DGHS

23. Dr. S.A.J.M. Musa, Assistant Director, Coordination, DGHS

24. Dr. Md. Anwar Hossain Munshi, Joint Chief, Health Economics Unit, MOHFW

25. Dr. Khaled Shamsul Islam, Senior Assistant Chief, HRD Unit, MOHFW

26. Mr. Abdul Hamid Moral, Assistant Chief, Health Economics Unit, MOHFW

27. Dr. Jafar Ahmad Hakim, Director, MCH Services \& Line Director, MC-RH, DGFP

28. Dr. Bishnupada Dhar, Program Manager, CA \& SS, DGFP

29. Mr. Mohammad Zearul Islam, Deputy Director, IEM, DGFP

30. Dr. Md. Rafiqul Islam, Civil Surgeon, Gaibandha

31. Dr. Md.Abdul Hakim, Civil Surgeon, Jamalpur

32. Dr. Md. Abdur Rashid Akanda, Civil Surgeon, Nilphamari

33. Dr. Md. Lokman Ali, Civil Surgeon, Thakurgaon

34. Dr. Md. Amirul Hassan, Head, Department of Public Health \& Hospital Administration, NIPSOM

35. Professor S.M. Shahnewaz Bin Tabib, Executive Director, ICMH

36. Ms. Shahin Sultana, Senior Research Associate, NIPORT

37. Dr. Jahiruddin Ahmed, Director General, Family Planning Association of Bangladesh (FPAB)

38. Dr. Aftab Uddin, Senior Manager, Technical Training Unit, ICDDRB \& Adjunct Faculty JPGSPH BRAC University

39. Dr. Emdadul Hoque, Deputy Project Coordinator, Child Health Unit, ICDDR,B

40. Dr. Anwar Islam, Professor \& Associate Dean, James P. Grant School of Public Health, BRAC University 
41. Dr. Farah M. Ahmed, Senior Lecturer \& Coordinator, CEP, James P. Grant School of Public Health, BRAC University

42. Dr. Enamul Hasib, Research Associate, James P. Grant School of Public Health, BRAC University

43. Ms. Nadia Ishrat Alamgir, Senior Research Associate, James P. Grant School of Public Health, BRAC University

44. Dr. Kaosar Afsana, Associate Director, BRAC Health Program

45. Dr. Chowdhury S.B. Jalal, Research Coordinator, Research Evaluation Division (RED), BRAC

46. Mr. Shah Noor Mahmud, Senior Sector Specialist, BRAC Health Program

47. Dr. Monowarul Aziz, Senior Medical Officer, BRAC Health Program

48. Dr. Rashedul H. Chowdhury, Sector Specialist, BRAC Health Program

49. Dr. Shamraj Arefin, CARE Bangladesh

50. Mr. Uzzal Kundu, Manager Services, Maries Stopes

51. Dr. Ladly K. Faiz, Chief Executive, PRDA

52. Dr. Ahmed Al-Kabir, President, RTM International

53. Mr. Moslehuddin Ahmed, Director, RTM International

54. Dr. Dildar Ahmed Khan, General Secretary, Bangladesh Neonatal Forum

55. Mr. Babul Kumar Adhikary, Team Leader, DORP MNH Rights Program

56. Professor Dr. Sushil Ranjan Howlader, Director, Institute of Health Economics, University of Dhaka

57. Dr. M. Kabir, Professor, Department of Statistics, Jahangir Nagar University

58. Dr. A.M. Zakir Hossain, Senior Consultant \& Team Leader, Project Preparation Cell, MOHFW

59. Mr. A.K.M. Zafar Ullah Khan, Former Member (Physical Infrastructure), Planning Commission

60. Dr. Md. Shahadat Hossain, Deputy Secretary, Government of Bangladesh

61. Dr. Nazrul Islam, Former Deputy Program Manager, EOC and DSF, DGHS

62. Brigadier General Dr. Abdus Shahid Khan, Former Director, DMCH

63. Professor U.H. Shahana Khatun, President, BMA, DMC

64. Ms. Rachel Payne, First Secretary AusAID

65. Mr. Shahrukh Safi, Sr. Program Officer (Health), AusAID

66. Dr. Shehlina Ahmed, Health Adviser, DFID

67. Dr. Noor Mohammad, Assistant Representative, Population and Development \& Gender, UNFPA

68. Dr. Hashina Begum, Assistant Representative, Reproductive Health, UNFPA

69. Dr. Atef El Maghraby, MNH Project Coordinator, UNFPA

70. Dr. Sanchay Chanda, Technical Officer, MNH, UNFPA

71. Ms. Yuki Suehiro, Deputy Representative, JICA

72. Ms. Yukie Yoshimara, CA, SMPP, JICA

73. Dr. Abdus Salam Khan, National Coordinator, DSF, WHO

74. Dr. Mahbube Khan, National Consultant, WHO

75. Mr. Christopher Heuschte, GFA Consulting Group

76. Dr. Palak, Health Economist, KfW/GFA

77. Dr. Lubana Ahmed, Health Specialist, Maternal Health/HIV Health \& Nutrition, UNICEF

78. Dr. Monira Parveen, Health Specialist, Health and Nutrition Section, UNICEF

79. Dr. Kazi Dil Afraoza Islam, Health Specialist, Health \& Nutrition, UNICEF

80. Dr. Md. Khairul Hasan, Health Officer, Maternal Health, UNICEF

81. Dr. Riad Mahmud, Health Officer, Health \& Nutrition Section, UNICEF

82. Dr. Ubaidur Rob, Country Director, Population Council

83. Dr. Sharif M. I. Hossain, Associate, Population Council

84. Ms. Ismat Bhuiya, Senior Program Officer, Population Council

85. Ms. Laila Rahman, Program Officer, Population Council

86. Dr. Ismat Ara Hena, Program Officer, Population Council

87. Mr. Md. Moshiur Rahman, Program Officer, Population Council 
88. Mr. Md. Noorunnabi Talukder, Program Officer, Population Council

89. Mr. Amar K. Baidya, Assistant Program Officer, Population Council

90. Mr. Mohammad Masudul Alam, Senior Research Officer, Population Council

91. Mr. Mohammad Ataur Rahman, Senior Research Officer, Population Council

92. Mr. Mohammad Mostafizur Rahman Khan, Senior Research Officer, Population Council

93. Ms. Farhana Akter, Senior Research Officer, Population Council

94. Ms. Tasnima Kibria, Senior Research Officer, Population Council 


\section{Participant List}

(Not according to seniority)

P4P Jamalpur District Workshop, 8 April 2010

1. Dr. A.B.M. Jahangir Alam, Director, PHC \& Line Director, ESD, DGHS

2. Dr. Kazi Md. Habibur Rahman, PM- Reproductive Health, DGHS

3. Dr. Akhter Jahan, DPM (MNH), RH, DGHS

4. Dr. Azizul Alim, DPM- EOC (VC), DGHS

5. Dr. Nazrul Islam, DPM, (EOC and DSF), DGHS

6. Dr. Md. Abdul Hakim, Civil Surgeon, Jamalpur

7. Dr. Saifuddin Ahmed, DCS, Civil Surgeon Office, Jamalpur

8. Dr. Fakhnia Alam, Consultant, Jamalpur General Hospital

9. Dr. Md. Nurul Islam Talukder, Jr. Consultant (Anesthesiology), Jamalpur General Hospital

10. Dr. Jatindra Chandra Mandal, RMO, Jamalpur General Hospital

11. Dr. Biresh C. Debnath, Medical Officer, CS Office, Jamalpur

12. Dr. Md. Rafiqul Islam Talukder, MO-MCHFP, Jamalpur General Hospital

13. Dr. Md. Tazul Islam, MO, Jamalpur General Hospital

14. Ms. Rehana Pervin, SSN, Jamalpur General Hospital

15. Ms. Renuara Khatun, SSN, Jamalpur General Hospital

16. Ms. Salma Khatun, SSN, Jamalpur General Hospital

17. Md. Mehedi Hassan, Head Assistant cum Accountant, CS office, Jamalpur

18. Md. Ainul Hoque, Statistician, CS office, Jamalpur

19. Mr. Md. Abu Hannan, Office Assistant, Jamalpur General Hospital

20. Dr. Nargis Begum, DD-FP, Jamalpur

21. Dr. A.H.M. Azizul Hoque, UHFPO, Bakshigonj UHC

22. Md. Golam Rabbani, UFPO, Bakshigonj UHC

23. Dr. Md. Mokhlesur Rahman, MO, Bakshigonj UHC

24. Ms. Hasna Akter, Senior FWV, Bakshigonj UHC

25. Ms. Mahmuda Siddika, SSN, Bakshigonj UHC

26. Mr. Md. Mehedi Hassan, Head Assistant, Bakshigonj UHC

27. Mr. Md. Mosharrof Hossen, Statistician, Bakshigonj UHC

28. Dr. Md. Gius Uddin, UHFPO, Malandah UHC

29. Dr. Mehedi Iqbal, RMO, Melandah UHC

30. Mr. Md. Rabiul Islam, MO, Melandah UHC

31. Ms. Feroza Begum, AFWO, Melandah UHC

32. Ms. Nazma Akter, SSN, Melandah UHC

33. Mr. Md. M. Alam Akhanda, Statistician, Melandah UHC

34. Mr. Md. Abdul Hakim, Head Assistant, Melandah UHC

35. Dr. Md. Feroze Khan, UH FPO, Islampur UHC

36. Mr. Md. Abdus Salam, UFPO, Islampur UHC

37. Dr. Mohammad Zahir Uddin, RMO (In-charge), Islampur UHC

38. Dr. Probal Sutradhar, MO, Islampur UHC

39. Ms. Rashada Akter, FWV, Islampur UHC

40. Mr. Md. Salim Reza, Statistician, Islampur UHC

41. Dr. Shamraj Arefin, CARE Bangladesh

42. Mr. Manaj Kumar Biswas, PM-MNH, CARE Bangladesh

43. Mr. Md. Zakir Hossain, District Manager, DORP

44. Dr. Riad Mahmud, UNIICEF

45. Dr. Rama Das, Project Officer, MNH, UNICEF

46. Ms. Hira Khanam, Program Officer, UNICEF

47. Ms. Nadia Ishrat Alamgir, Sr. Research Associate, JPGSPH, BRAC University 
48. Dr. Ubaidur Rob, Country Director, Population Council

49. Ms. Laila Rahman, Program Officer, Population Council

50. Dr. Ismat Ara Hena, Program Officer, Population Council

51. Mr. Md. Moshiur Rahman, Program Officer, Population Council

52. Mr. Md. Noorunnabi Talukder, Program Officer, Population Council

53. Mr. Mohammad Masudul Alam, Senior Research Officer, Population Council

54. Mr. Mohammad Ataur Rahman, Senior Research Officer, Population Council 


\section{Participant List \\ (Not according to seniority)}

P4P Gaibandha District Workshop, 3 May 2010

1. Dr. A.B.M. Jahangir Alam, Director, PHC \& Line Director, ESD, DGHS

2. Dr. Kazi Md. Habibur Rahman, Program Manager, Reproductive Health, DGHS

3. Dr. Nazrul Islam, DPM, EOC and DSF, DGHS

4. Dr. Jafar Ahmad Hakim, Director, MCH Services \& Line Director, MC-RH, DGFP

5. Dr. Md. Rafiqul Islam, Civil Surgeon, Gaibandha

6. Dr. Amal Chandra Saha, Consultant- Gynae (in charge), District Hospital, Gaibandha

7. Dr. Yusuf Harun Ar Rashid, Consultant-Pediatric, District Hospital, Gaibandha

8. Dr. Md. Aminul Islam, Resident Medical Officer, District Hospital, Gaibandha

9. Dr. ABM Abu Hanif, Medical Officer, District Hospital, Gaibandha

10. Dr. ShamimaBegum, Medical Officer, District Hospital, Gaibandha

11. Dr. Afsari Khanam, Medical Officer-Clinic, Gaibandha

12. Dr. AKM Asaduzzaman, Medical Officer-MCH, Gaibandha

13. Mr. Bina Pani Golder, Senior Staff Nurse, District Hospital, Gaibandha

14. Mr. Md. Asaduzzaman Pramanik, Statistician, District Hospital, Gaibandha

15. Md. Alhaz Ali Akand, MT-Lab, District Hospital, Gaibandha

16. Dr. Ferdous Hossain Manju, DD-Family Planning, Gaibandha

17. Dr. Shah Md. Wajed Ali, Upazila Health and Family Planning Officer, Upazila Health Complex, Sunderganj, Gaibandha

18. Mr. Md. Ansar Ali, Upazila Family Planning Officer, Upazila Health Complex, Sunderganj, Gaibandha

19. Ms. Halima Khatun, Assistant Upazila Family Planning Officer, Upazila Health Complex, Sunderganj, Gaibandha

20. Ms. Sabina Yeasmin, Senior Staff Nurse, Upazila Health Complex, Sunderganj, Gaibandha

21. Mr. Kunjalata Paul, Statistician, Upazila Health Complex, Sunderganj, Gaibandha

22. Dr. Ismail Hossain, Upazila Health and Family Planning Officer (in charge), Upazila Health Complex, Saghata, Gaibandha

23. Md. Quayyum Ali, Upazila Family Planning Officer, Upazila Health Complex, Saghata, Gaibandha

24. Dr. Asiqur Rahman, Medical Officer, Upazila Health Complex, Saghata, Gaibandha

25. Ms. Kahinoor Begum, Senior Staff Nurse, Upazila Health Complex, Saghata, Gaibandha

26. Md. Sadrul Islam, Statistician, Upazila Health Complex, Saghata, Gaibandha

27. Dr. Md. Akhtaruzzaman, Upazila Health and Family Planning Officer, Upazila Health Complex, Fulchhari, Gaibandha

28. Dr. Aby Syed Mustaq Ahmed, Upazila Family Planning Officer (in charge), Upazila Health Complex, Fulchhari, Gaibandha

29. Anzuman Ara Begum, Assistant Upazila Family Planning Officer, Upazila Health Complex, Fulchhari, Gaibandha

30. Dr. Sonaullah Mondal, Resident Medical Officer, Upazila Health Complex, Fulchhari, Gaibandha

31. Dr. Shafiul Hossain, Medical Officer, Upazila Health Complex, Fulchhari, Gaibandha

32. Mst. Halima Khatun, Senior Staff Nurse, Upazila Health Complex, Fulchhari, Gaibandha

33. Sree Prabir Kumar Gun, Statistician, Upazila Health Complex, Fulchhari, Gaibandha

34. Dr. Sahiduzzaman Harun, President, BMA, Gaibandha

35. Dr. Farah Mahjabin Ahmed, Senior Lecturer \& Coordinator, CEP, James P. Grant School of Public Health, BRAC University 
36. Ms. Nadia Ishrat Alamgir, Senior Research Associate, James P. Grant School of Public Health, BRAC University

37. Mr. Shah Noor Mahmud, Senior Sector Specialist, BRAC Health Program, BRAC

38. Dr. Rashedul H. Chowdhury, Sector Specialist, BRAC Health Program, BRAC

39. Mr. Rabindranath Sarkar, District Manager, MNCH Program, (Maa, Nobojatok O Sishu Sasthya Unnayan Karmasuchi), BRAC, Gaibandha

40. Ms. Bilkis Ara Khanam, District Manager, MNCH Program, (Maa, Nobojatok O Sishu Sasthya Unnayan Karmasuchi), BRAC, Gaibandha

41. Mr. Uttum Kumar Chawdhury, Clinic Coordinator, Marie Stopes Clinic Society, Gaibandha

42. Mr. Joya Prasad, Project Manager, Domestic Violence Project, Gono Unnayan Kendra, Gaibandha

43. Mr. Surojit Kumar, Program Associate, Gono Unnayan Kendra, Gaibandha

44. Mr. A.H.M. Samsuzzaman Azad, Project Manager, CLP, Friendship, Gaibnadha

45. Dr. Lubana Ahmed, Health Specialist, Maternal Health/HIV Health \& Nutrition, UNICEF Bangladesh

46. Dr. Md. Khairul Hasan, Health Officer, Maternal Health, UNICEF Bangladesh

47. Mr. Fahim U. Ahmed, P.O., UNICEF Bangladesh

48. Dr. Uabidur Rob, Country Director, Population Council

49. Dr. Ismat Ara Hena, Program Officer, Population Council

50. Mr. Md. Moshiur Rahman, Program Officer, Population Council

51. Ms. Farhana Akter, Senior Research Officer, Population Council 


\section{Participant List \\ (Not according to seniority) \\ P4P Nilphamari District Workshop, 2 May 2010}

1. Dr. A.B.M. Jahangir Alam, Director, PHC \& Line Director, ESD, DGHS

2. Dr. Jafar Ahmed Hakim, Director, MCH \& Line Director, MC-RH, DGFP

3. Dr. Kazi Habibur Rahman, Program Manager, R H, DGHS

4. Dr.Md. Abdur Rashid Akand, Civil Surgeon

5. Dr. Shah Md. Moazzem Hossain, DCS/MO-CS, Nilphamari District Hospital

6. Dr. Md. Khorshed Alam, RMO, Nilphamari District Hospital

7. Dr. Selina Begum, Consultant-Gynecology and Obstetrics, Nilphamari District Hospital

8. Dr. Md. Enamul Haque, Consultant-Pediatrics, Nilphamari District Hospital

9. Dr. Dilip Kumar Roy, MO-Child, Nilphamari District Hospital

10. Ms. Ayesha Siddika, Senior Staff Nurse (Labor), Nilphamari District Hospital

11. Ms. Jotsna Banu, Senior Staff Nurse (Child), Nilphamari District Hospital

12. Mr. Mahbub Rabbani, Statistician, CS Office, Nilphamari

13. Mr. Md. Abdul Baset, Steno, CS Office, Nilphamari

14. Mr. Md. Mizanur Rahman, D.S.I., Nilphamari District Hospital

15. Ms. Afroza Begum, DD-FP, Nilphamari

16. Dr. Ehsanul Haque, AD-CC, Nilphamari

17. Dr. Din Mohammad, UHFPO, Dimla Upazila Health Complex

18. Dr. Sunjeda Akhter, MO, Dimla Upazila Health Complex

19. Dr. Samsher Ali Mia, MO-MCH, Dimla Upazila Health Complex

20. Ms. Latifa Yesmin, Senior Staff Nurse, Dimla Upazila Health Complex

21. Mr. Md. Jhurul Haque, Statistician, Dimla Upazila Health Complex

22. Ms. Julekha Khanam, UFPO, Dimla Upazila Health Complex

23. Ms. Mahmuda Begum, AFWO, Dimla Upazila Health Complex

24. Dr. Md. Anwarul Islam,UHFPO, Domar Upazila Health Complex

25. Dr. Md. Hasinur Rahman, RMO, Domar Upazila Health Complex

26. Dr. Md. Ruhul Amin, MO, Domar Upazila Health Complex

27. Dr. Nihar Ranzan Saha, MO, Domar Upazila Health Complex

28. Ms. Rebeka Sultana, Senior Staff Nurse, Domar Upazila Health Complex

29. Ms. Laila Yasmin Chowdhury, Statistician, Domar Upazila Health Complex

30. Mr. Md. Abu Zafar, UFPO, Domar Upazila Health Complex

31. Ms. Sahana Begum, AFWO, Domar Upazila Health Complex

32. Dr. Md. Gowsal Azam, UHFPO, Jaldhaka Upazila Health Complex

33. Dr. Md. Nurul Islam, RMO, Jaldhaka Upazila Health Complex

34. Dr. Md. Mizanur Rahman, MO, Jaldhaka Upazila Health Complex

35. Mr. Md. Azharul Islam, Statistician/Accountant, Jaldhaka Upazila Health Complex

36. Mr. S.M. Ahsanul Haque, UFPO, Jaldhaka Upazila Health Complex

37. Mrs. Sufia Begum, FWV, Jaldhaka Upazila Health Complex

38. Dr. M. A. Mojid Sarker, UHFPO, Sadar Upazila

39. Mr. Md. Makbul Hossain, UFPO, Sadar Upazila

40. Dr. Md. Sekander Ali, MO (MCH-FP), Sadar Upazila

41. Dr. Rokshana Begum, MO-Clinic, Maternal and Child Welfare Center, Nilphamari

42. Mr. Md. Zillur Rahman, PO (MNCH), BRAC

43. Mr. Rabindra Nath Sarker, District Manager-MNCH, BRAC

44. Dr. Rashedul Haider Chowdhury, Sector Specialist, BRAC Health Program

45. Dr. Monowarul Aziz, Senior Medical Officer, BRAC Health Program 
46. Dr. Farah M. Ahmed, James P. Grant School of Public Health, BRAC University

47. Mr. Shah Noor Mahmud, Sr. Regional Manager, BRAC

48. Mr. Md. Asaduzzaman, Leprosy Control Supervisor

49. Dr. A.F.M. Mostafa Sarker, PD-SSFP, Kanchan Samity

50. Mr. Md. Najmus Sakib, Clinic Manager, Smiling Sun Clinic

51. Mr. Md. Ashraful Alam, Clinic Manager, Marie Stopes Clinic

52. Mr. Fahim Uddin Ahmed, Program Officer, UNICEF/Rangpur

53. Dr. Mohammad Khairul Hasan, Health Officer (Maternal Health), UNICEF

54. Ms. Salma Begum, HI, Women Friendly Hospital, Nilphamari

55. Dr. Nazrul Islam, Former DPM, EOC \& DSF, DGHS

56. Dr. Lubana Ahmed, UNICEF Bangladesh

57. Dr. Ubaidur Rob, Country Director, Population Council

58. Dr. Ismat Ara Hena, Program Officer, Population Council

59. Mr. Md. Moshiur Rahman, Program Officer, Population Council

60. Mr. Mohammad Ataur Rahman, Senior Research Officer, Population Council 


\section{Participant List \\ (Not according to seniority) \\ P4P Kurigram District Workshop, 9 August 2010}

1. Dr. Iqbal Ahmed, DPM, RH, DGHS

2. Dr. Md. Omar Ali Sarkar, DPM $1^{\text {st }}$ ESP) DGHS

3. Dr. Md Golam Mostafa, Civil Surgeon, Kurigram

4. Dr. Md. Mustafizur Rahman, Jr. Consultant, Kurigram District Hospital

5. Dr. Mahbuba Khatun, Jr. Consultant, (obstetrics and gynecology) Kurigram District Hospital

6. Dr. Moktar Ali, Jr. Consultant (pediatrics), Kurigram ,District Hospital

7. Dr. K.K. Paul , RMO, Kurigram District Hospital

8. Dr. Nirmolendu Roy, MO-CS, Kurigram ,District Hospital

9. Ms. Sheikh Shefali Rahman, Sr. Staff Nurse, Kurigram District Hospital

10. Ms. Mst. Rina Begum, Sr. Staff Nurse, Kurigram District Hospital

11. Md. Abdul Kader,Sr. HEO, CS office, Kurigram

12. Dr. Nazrul Islam, MO, Kurigram District Hospital

13. Dr. Md. Zahangir Alam, MO, Kurigram District Hospital

14. Dr. Arifa Begum, MO, Kurigram District Hospital

15. Md. Shafiar Rahman, P.O. CS Office, Kurigram District Hospital

16. Dr. Md. Shamsuddoha, DD-FP, Kurigram

17. Dr. Upendranath Shil,UH\&FPO, UHC, Bhurangamari

18. Dr. Md. Tofazzal Hossain, UFPO, UHC, Bhurangamari

19. Md. Nurul Haque Chowdhury, UFPO, UHC, Bhurangamari

20. Dr. Md. Hafizur Rahman, UH\&FPO, UHC, Nageshwari

21. Dr. Md. Amzad Hossain, RMO, UHC, Nageshwari

22. Dr. Bilkis Begum, MO, UHC, Nageshwari

23. Md. Anwar Ali, UFPO, UHC, Nageshwari

24. Dr. Motasim Billah Azad, UH\&FPO, UHC, Chilmari

25. Md. Abdul Halim Sarkar, UFPO, Chilmari

26. Dr. Md. Nazrul Islam, Ex. DPM (RH \& EOC) DGHS

27. Md. Shariful Islam, Program Officer, TDH

28. Dr. Monowarul Aziz, Senior Technical Officer, BRAC, Dhaka

29. Karan Courtrey, UNICEF (MH)

30. Dr. Md. Shafiul Alam, SMO- WHO

31. Dr. Md. Maksudul Amin, DIMO-GAVI

32. Dr. Ubaidur Rob, Population Council

33. A.K.M. Zafar Ulla Khan, Population Council

34. Dr. Ismat Ara Hena, Population Council

35. Md. Julkarnayeem, Population Council 


\section{Annexure 3: Target Beneficiaries}

Table 1 Target Beneficiaries at District Hospital

\section{Target beneficiaries}

Managers

Civil Surgeon/ Superintendent

Direct service providers

Senior Consultant (Gynecology \& Obstetrics)

Senior Consultant (Pediatrics)

Resident Medical Officer (RMO)

Jr. Consultant (Gynecology \& Obstetrics)

Jr. Consultant (Anesthesia)

MO (Anesthesia)

Asst. Register (Gynecology \& Pediatrics)

Emergency Medical Officer

Medical Officer (Blood Bank)

Medical Officer (Gynecology \& Pediatrics)

Sr. Staff Nurse

Indirect providers

Consultant (Radiology)

Consultant (Pathology)

Medical Technologist (Lab)

Medical Technologist (Blood bank)

Medical Technologist (Radiography)

Pharmacist

\section{Administrative staff}

Deputy Nursing Superintendent/

Nursing Supervisor

Head Assistant-cum-Accountant

Statistician

Store Keeper

MLSS

\section{Support staff}

Ward boy

Aya

Cook/Mashalchi

Sweeper

Security Guard

Stretcher Bearer

Ambulance driver
Level of effort (\%) Proposed benefit ratio

100

100

100

100

100
50

50

50

50

Note: Level of effort of DD-FP will be $100 \%$ with benefit ratio of 100 . The benefit ratio of the designated persons who will keep record and make payment against coupon and incentives, and distribute medicines will be considered 100. The field workers including Family Welfare Assistants (FWAs), Health Assistants (HA) and NGO workers will receive Taka 50 for each successful MNCH complications related referral case. 
Table 2 Target Beneficiaries at Upazila Health Complex

\begin{tabular}{|c|c|c|}
\hline Target beneficiaries & Level of effort (\%) & Proposed benefit ratio \\
\hline $\begin{array}{l}\text { Managers } \\
\text { UHFPO } \\
\text { UFPO/AUFPO }\end{array}$ & 100 & 100 \\
\hline $\begin{array}{l}\text { Direct providers } \\
\text { Jr. Consultant (Gynecology \&Obstetric) } \\
\text { Jr. Consultant (Pediatrics) } \\
\text { Jr. Consultant (Anesthesia)/MO (Anesthesia) } \\
\text { MO (MCH-FP) } \\
\text { RMO } \\
\text { Medical Officer } \\
\text { Medical Officer (Disease Control) } \\
\text { Sr. Staff Nurse } \\
\text { AFWO/Sr. FWV } \\
\text { Medical Assistant }\end{array}$ & 100 & 100 \\
\hline $\begin{array}{l}\text { Indirect providers } \\
\text { Pathologist } \\
\text { Medical Technologist (Radiography) } \\
\text { Medical Technologist (Lab) } \\
\text { EPI Technician } \\
\text { Pharmacist }\end{array}$ & 50 & 50 \\
\hline $\begin{array}{l}\text { Administrative staff } \\
\text { Head Assistant-cum-Accountant } \\
\text { Statistician } \\
\text { Store Keeper } \\
\text { MLSS }\end{array}$ & 50 & 50 \\
\hline Support staff & & \\
\hline Ward boy & 100 & 100 \\
\hline Aya & 100 & 100 \\
\hline Cook/Mashalchi & 50 & 50 \\
\hline Sweeper & 100 & 100 \\
\hline Security Guard & 50 & 50 \\
\hline Ambulance driver & 100 & 100 \\
\hline
\end{tabular}

Note: The benefit ratio of the designated persons who will keep record and make payment against coupon and incentives, and distribute medicines will be considered 100. The field workers including Family Welfare Assistants (FWAs), Health Assistants (HA) and NGO workers will receive Taka 50 for each successful MNCH complications related referral case. 


\section{Few Special Moments of the National Workshop}

(BRAC Center Inn, Mohakhali, Dhaka, 31 March, 2010) 

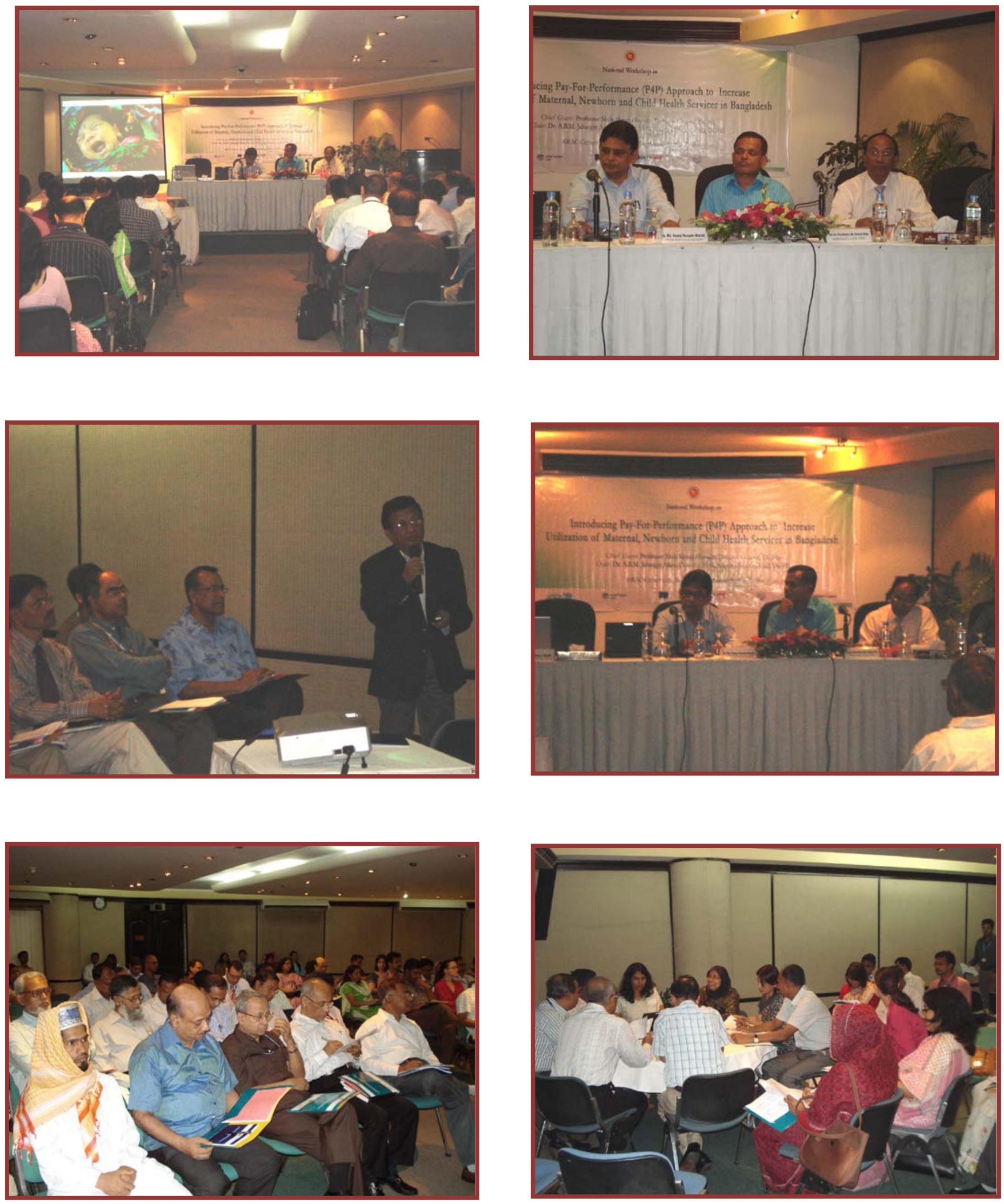

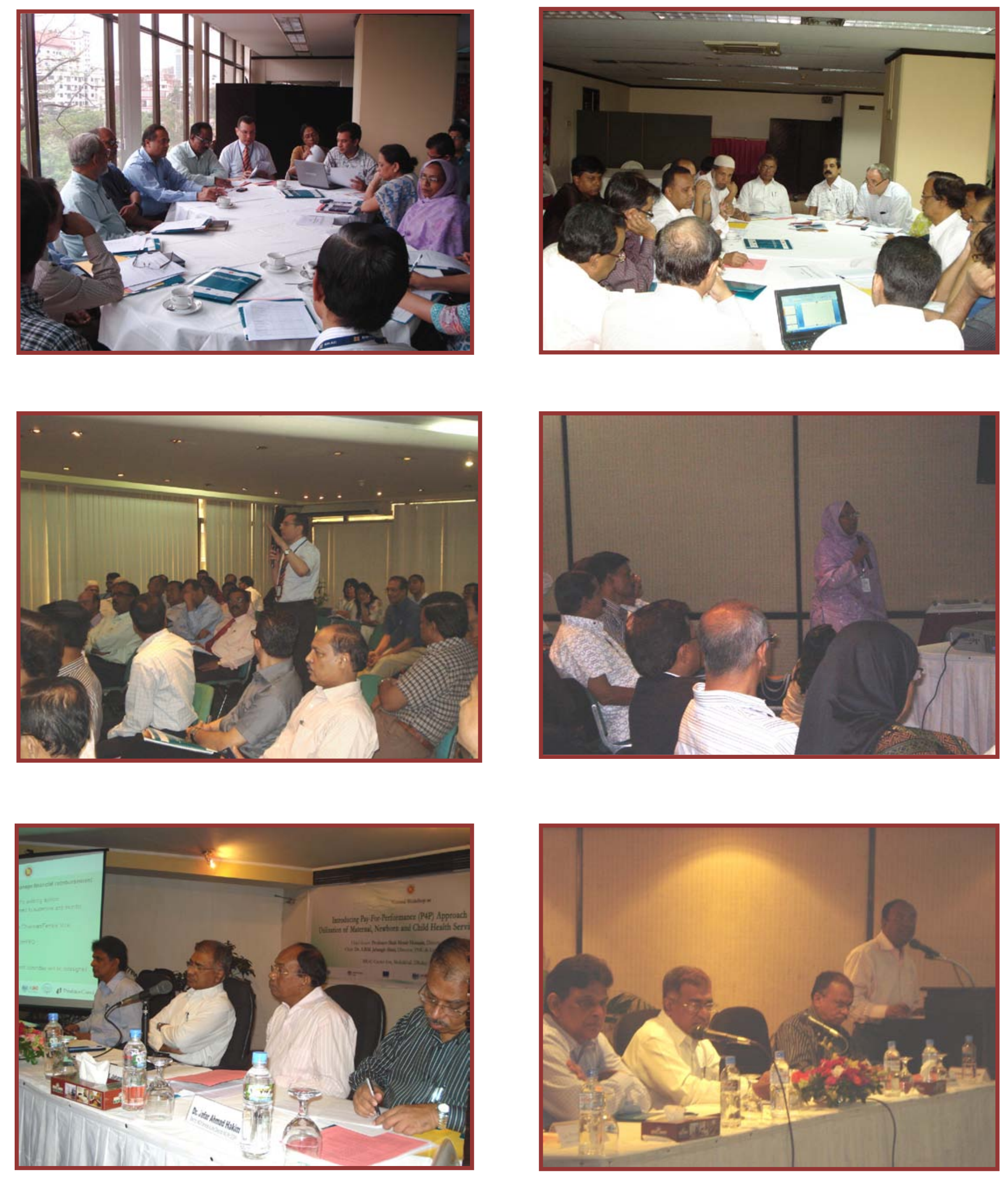
A Population Council

www.popcouncil.org

South \& East Asia - Bangladesh Office

House CES(B) 21, Road 118

Gulshan, Dhaka, Bangladesh

Phone : $8802-8821227,8826657$

Fax : 8802-8823127

Email : info.bangladesh(apopcouncilorg 